\title{
Hypoactivation of CRF Receptors, Predominantly Type 2, in the Medial-Posterior BNST Is Vital for Adequate Maternal Behavior in Lactating Rats
}

\author{
Stefanie M. Klampfl, ${ }^{1}$ Paula J. Brunton, ${ }^{2}$ Doris S. Bayerl, ${ }^{1}$ and Oliver J. Bosch ${ }^{1}$ \\ ${ }^{1}$ Department of Behavioural and Molecular Neurobiology, University of Regensburg, 93053 Regensburg, Germany, and ${ }^{2}$ Division of Neurobiology, The \\ Roslin Institute and Royal (Dick) School of Veterinary Studies, University of Edinburgh, Easter Bush, Midlothian, EH25 9RG, United Kingdom
}

\begin{abstract}
Maternal behavior ensures the proper development of the offspring. In lactating mammals, maternal behavior is impaired by stress, the physiological consequence of central corticotropin-releasing factor receptor (CRF-R) activation. However, which CRF-R subtype in which specific brain area(s) mediates this effect is unknown. Here we confirmed that an intracerebroventricularly injected nonselective CRF-R antagonist enhances, whereas an agonist impairs, maternal care. The agonist also prolonged the stress-induced decrease in nursing, reduced maternal aggression and increased anxiety-related behavior. Focusing on the bed nucleus of the stria terminalis (BNST), CRF-R1 and CRF-R2 mRNA expression did not differ in virgin versus lactating rats. However, CRF-R2 mRNA was more abundant in the posterior than in the medial BNST. Pharmacological manipulations within the medial-posterior BNST showed that both CRF-R1 and CRF-R2 agonists reduced arched back nursing (ABN) rapidly and after a delay, respectively. After stress, both antagonists prevented the stressinduced decrease in nursing, with the CRF-R2 antagonist actually increasing ABN. During the maternal defense test, maternal aggression was abolished by the CRF-R2, but not the CRF-R1, agonist. Anxiety-related behavior was increased by the CRF-R1 agonist and reduced by both antagonists. Both antagonists were also effective in virgin females but not in males, revealing a sexual dimorphism in the regulation of anxiety within the medial-posterior BNST. In conclusion, the detrimental effects of increased CRF-R activation on maternal behavior are mediated via CRF-R2 and, to a lesser extent, via CRF-R1 in the medial-posterior BNST in lactating rats. Moreover, both CRF-R1 and CRF-R2 regulate anxiety in females independently of their reproductive status.
\end{abstract}

\section{Introduction}

The maternal brain is a complex and perfectly organized system that undergoes vital adaptations peripartum to ensure the onset and maintenance of maternal behavior (Bosch, 2011). Therefore, maladaptive alterations can cause severe problems such as increased vulnerability to mood disorders, which affect $20-30 \%$ of mothers (Brummelte and Galea, 2010). One factor that evidently contributes to such maladaptations is corticotropin-releasing factor (CRF; Magiakou et al., 1996; O'Keane et al., 2011).

CRF is a 41 amino acid neuropeptide that binds to the CRF type-1 receptor (CRF-R1) and has 40-fold lower affinity to CRF-R2 (Hauger et al., 2003), which is primarily activated by

\footnotetext{
Received Oct. 2, 2013; revised June 5, 2014; accepted June 11, 2014.

Author contributions: S.M.K. and 0.J.B. designed research; S.M.K., P.J.B., D.S.B., and 0.J.B. performed research; S.M.K. and 0.J.B. analyzed data; S.M.K., P.J.B., and 0.J.B. wrote the paper.

We thank Helen Cameron, Ines Kobor, and Gabriele Schindler for excellent technical support and Michael Lukas and Michael Bowen for expert statistical discussions and guidance. Further, we thank Inga Neumann for continuous support. This work was funded in part by the BBSRC (BB/J004332/1) to P.J.B.

The authors declare no competing financial interests.

This article is freely available online through the J Neurosci Author Open Choice option.

Correspondence should be addressed to Dr. Oliver J. Bosch, Department of Behavioural and Molecular Neurobiology, University of Regensburg, 93053 Regensburg, Germany. E-mail: oliver.bosch@ur.de.

DOI:10.1523/JNEUROSCI.4220-13.2014

Copyright $\odot 2014$ Klampfl et al.

This is an Open Access article distributed under the terms of the Creative Commons Attribution License (http://creativecommons.org/licenses/by/3.0), which permits unrestricted use, distribution and reproduction in any medium provided that the original work is properly attributed.
}

urocortin 2 (Ucn 2) and Ucn 3 (Hsu and Hsueh, 2001; Lewis et al., 2001; Reyes et al., 2001). CRF is the primary initiator of the hypothalamo-pituitary-adrenal axis (Vale et al., 1981). Furthermore, CRF exerts anxiogenic actions via CRF-R1 when centrally injected (Koob and Thatcher-Britton, 1985; Bruchas et al., 2009) or locally injected, for example, into the bed nucleus of the stria terminalis (BNST) of male rats (Lee and Davis, 1997; Liang et al., 2001; Sahuque et al., 2006). The CRF system also modulates male social behaviors including aggression (Mele et al., 1987; Tazi et al., 1987) and social recognition (Heinrichs, 2003). In females, activated CRF-Rs impair maternal behavior, as reported in a few studies in rodents (Pedersen et al., 1991; Gammie et al., 2004; D’Anna et al., 2005; D'Anna and Gammie, 2009; Klampfl et al., 2013) and primates (Saltzman et al., 2011). In lactating mice, intracerebroventricular administration of CRF or Ucn 3 decreases maternal aggression (Gammie et al., 2004; D'Anna et al., 2005), which has been linked to CRF-R2 activation in the lateral septum (D'Anna and Gammie, 2009). In ovariectomized, steroid-primed virgin rats, intracerebroventricular CRF decreases maternal-like behavior and induces pup killing (Pedersen et al., 1991), which is not observed in lactating rats (Klampfl et al., 2013). In the latter, intracerebroventricular CRF$\mathrm{R} 1 / 2$ activation decreases maternal care and aggression and increases anxiety-related behavior, whereas CRF-R1/2 inhibition restores maternal care after stress and is anxiolytic (Klampfl et al., 2013). However, the potential brain sites of action and the specific role of the 
different CRF-R subtypes in maternal behavior and anxiety-related behavior in lactating rats are not known.

Here, we first aimed to confirm our finding of impaired maternal behavior after central manipulation of CRF-R1/2 (Klampfl et al., 2013) using a different, more nonspecific receptor agonist. Thereafter, we focused on the BNST, a key brain region for maternal behavior (Terkel et al., 1979; Numan et al., 1985) and anxiety behavior (Lee and Davis, 1997), which expresses most members of the CRF family (Potter et al., 1992; Potter et al., 1994; Li et al., 2002). We assessed CRF-R1 and CRF-R2 mRNA expression in the medial (mBNST) and posterior (pBNST) BNST of virgin and lactating rats. Based on these results, we studied maternal care, motivation, aggression, and emotionality in lactating rats after local pharmacological manipulation with CRF-R1 and CRF-R2 specific agonists/antagonists in the medial-posterior BNST (mpBNST). In addition, we investigated a potential sexual dimorphism in the regulation of anxiety-related behavior within the mpBNST in rats.

\section{Materials and Methods}

\section{Animals}

Virgin female or male Wistar rats (220-250 g; Charles River Laboratories) were kept under standard laboratory conditions (change of bedding once per week, 12/12 h light/dark cycle, lights on at 6:00 A.M., room temperature $22 \pm 2{ }^{\circ} \mathrm{C}, 55 \%$ relative humidity) with access to water and standard rat chow ad libitum. For Experiments 1-3, females were mated and housed until delivery as described previously (Klampfl et al., 2013). Litters were culled to eight pups of mixed sexes. For comparison of virgin females versus lactating rats in Experiment 2, both groups were treated identically; that is, virgins were single housed $7 \mathrm{~d}$ before brain removal, consistent with the single-housing period of the lactating rats. For Experiments 4 and 5, virgin female and male rats were kept in groups of 3-4 until surgery, whereafter they were single housed as described previously (Klampfl et al., 2013). During the single-housing period, all rats were handled twice a day to reduce nonspecific stress responses during the experiments (Neumann et al., 1998).

For the maternal defense test, naive virgin female rats (200-220 g; Charles River Laboratories) were used as intruders at random stages of their estrus cycle. Intruder rats were kept in a separate room to avoid olfactory recognition.

The experiments were approved by the Committee on Animal Health and Care of the local government and conformed to international guidelines on the ethical use of animals. All efforts were made to minimize the number of rats used and their suffering.

\section{Behavioral tests}

Maternal care. Maternal care was monitored on lactation day 1 (LD1) before and after substance infusion under nonstress conditions and on LD5 before and after substance infusion, which was combined with a psychosocial stressor (stress conditions; i.e., maternal defense test; Neumann et al., 2005). We acknowledge that there is a limited amount of stress associated with the infusion procedure, though the nonstress term is used to distinguish between the observations made on LD1, which did not involve the maternal defense test, from those conducted on LD5, which did. Observations were conducted for 10 s every second min in 30 min blocks according to an established protocol (Bosch and Neumann, 2008). On LD1, dams were observed from 8:00-9:00 A.M., infused at 9:00 A.M., and observation continued from 9.30-11:00 A.M. In addition, dams were observed from 2:00-3:00 P.M. to assess potential longlasting effects of drug treatment. On LD5, dams were observed from 8:00-9:00 A.M., transported to another room, and infused at 10:00 A.M. Dams were tested $30 \mathrm{~min}$ after infusion in the maternal defense test, transported back to the observation room immediately afterward, and maternal care was observed for another $60 \mathrm{~min}$ to assess potential effects of the stressor on maternal care. The main parameter for the quality of maternal care was the occurrence of arched back nursing (ABN; Bosch, 2011; Bosch and Neumann, 2012), the only active nursing posture in which the dam is engaged in a quiescent kyphosis (Stern and Johnson,
1990). Other nursing parameters scored were hovering over the pups and blanket nursing posture, which together with $\mathrm{ABN}$ were counted as the sum of nursing, indicating the quantity of maternal care because both active and passive nursing postures were included. Pup retrieval/mouthing and licking/grooming were assessed as "other maternal behaviors." In addition, the following nonmaternal behaviors were scored: locomotion (including digging/burrowing and cage exploration), self-grooming, and sleeping/resting, which were summed up and are presented as "off-nest" behavior. Data are shown in 30 min blocks before and after treatment infusion with a maximal count of 15 observations per block.

Maternal motivation. The dams' maternal motivation was tested in the pup retrieval test (PRT) on LD2 (van Leengoed et al., 1987; Neumann et al., 2005). The dams were separated from their litter $60 \mathrm{~min}$ before the test and moved to a separate room. Thirty minutes before the test, dams received their respective treatment. All eight pups of the litter were then distributed in a plastic box $(54 \times 34 \times 31 \mathrm{~cm})$ covered with bedding from their home cage, the mother was placed in the box, and the number of retrieved pups within the 15 min testing period was counted.

Maternal aggression. To assess maternal aggression, the maternal defense test was performed on LD5 in a separate room, to which the dams were transported $60 \mathrm{~min}$ before the test (see Maternal care, above). Thirty minutes after treatment infusion, the lactating residents were confronted with an unknown virgin female intruder in their home cage in the presence of the litter for $10 \mathrm{~min}$, as described previously (Neumann et al., 2001; Bosch et al., 2005). The dam's behavior was videotaped for subsequent analysis by an experienced observer blinded to the treatment. The following behavioral parameters were scored: total number of attacks, latency to first attack, keep down, lateral threat, and offensive upright, and nonaggressive behaviors (for detailed description, see Bosch, 2013).

Anxiety-related behavior. Anxiety-related behavior was tested on the elevated plus maze (EPM) on LD3 in lactating rats and additionally in virgin female and male rats as described previously (Pellow et al., 1985; Neumann et al., 2000). Male rats were also tested in the light dark box (LDB; adapted from Waldherr and Neumann, 2007; Slattery and Neumann, 2010).

The EPM consists of two open arms $(50 \times 10 \mathrm{~cm}, 80 \mathrm{lux})$ and two closed arms $(50 \times 10 \times 30 \mathrm{~cm}, 10 \mathrm{lux})$ connected by a square-shaped neutral zone $(10 \times 10 \mathrm{~cm}, 65 \mathrm{lux})$ and is elevated $82 \mathrm{~cm}$ from the floor. The rats were placed in the neutral zone of the maze and were allowed to freely explore the maze for $5 \mathrm{~min}$. The percentage of time spent on the open arms (ratio of time spent on open arms to total time spent on all arms) and the percentage of open arm entries (ratio of entries into open arms to total number of entries into all arms) were taken as an indicator of anxiety-related behavior. An entry was recorded when both front legs and shoulders of the rat crossed into an arm or the neutral zone. Because the rat always had to cross the neutral zone, every open/closed arm entry was considered as a new entry. The number of closed arm entries was used to measure locomotion (Neumann et al., 2000).

The LDB consists of a light $(40 \times 50 \mathrm{~cm}, 400$ lux $)$ and a dark compartment $(40 \times 30 \mathrm{~cm}, 50$ lux $)$. A small opening $(7.5 \times 7.5 \mathrm{~cm})$ connecting both compartments enables transition between the light and dark box. The floor in each compartment is divided into squares $(10 \times 10 \mathrm{~cm})$ to assess locomotor activity via line crosses. The rats were placed in the light box and the time spent in each box, latency to enter the dark box and to reenter the light box, line crosses, and rearings were assessed during the $5 \mathrm{~min}$ test.

\section{Experimental design}

Experiment 1: Nonspecific intracerebroventricular manipulation of CRF$R 1 / 2$ in lactating rats. On pregnancy day 18 (PD18), females were implanted with a $21 \mathrm{G}$ guide cannula targeting the right lateral ventricle (1.0 $\mathrm{mm}$ caudal, $1.6 \mathrm{~mm}$ lateral, $1.8 \mathrm{~mm}$ ventral to bregma; Paxinos and Watson, 1998) under inhalation anesthesia (isoflurane; Baxter Germany) and semisterile conditions as described previously (Bosch et al., 2010). On the experimental days, a $23 \mathrm{G}$ infusion cannula, prepared as described previously (Neumann et al., 2000), was used to infuse the following: vehicle (VEH; $5 \mu \mathrm{l}$ of sterile Ringer's solution $+4 \%$ DMSO; $\mathrm{pH} 7.4$; Braun), the nonspecific CRF-R1/2 agonist Ucn 1 ( $1 \mu \mathrm{g} / 5 \mu \mathrm{l}$; Bachem), or the nonspecific CRF-R1/2 antagonist D-Phe (D-Phe ${ }^{12}, \mathrm{Nle}^{21,38}, \alpha$-Me$\mathrm{Leu}^{37}$ )-CRF (12-41, human/rat; $10 \mu \mathrm{g} / 5 \mu \mathrm{l}$; Bachem). Doses were chosen based on previous studies (Jones et al., 1998; Gammie et al., 2004). 
On LD1, LD2, LD3, and LD5, lactating dams received a single acute intracerebroventricular infusion $30 \mathrm{~min}$ before the tests. Each animal received the same treatment on every testing day as assigned on the first testing day. In each case, dams were immediately returned to their home cage after infusion. Maternal care was observed under nonstress conditions (LD1) and stress conditions (LD5) in the home cage, as described in Maternal care, above. In addition, maternal motivation (LD2), anxietyrelated behavior (LD3), and maternal aggression (LD5) were tested as described in Behavioral tests, above. All tests were performed between 8:00 A.M. and 3:00 P.M. in the light phase of the cycle.

Experiment 2: Expression of CRF-R1 and CRF-R2 $m R N A$ within the BNST of virgin versus lactating rats. To compare mRNA expression of CRF-R1 and CRF-R2 between virgin and lactating rats, two separate groups of untreated rats were killed by conscious decapitation under basal conditions on LD4 or equivalent in virgin rats. The brains were rapidly removed, flash frozen on dry ice, and stored at $-20^{\circ} \mathrm{C}$ until subsequent processing by in situ hybridization, as described in In situ hybridization, below.

Experiment 3: Intra-mpBNST manipulation of CRF-R1 or CRF-R2 in lactating rats. On PD18, females were implanted bilaterally with $23 \mathrm{G}$ guide cannula targeting the pBNST $(0.7 \mathrm{~mm}$ caudal, $1.5 \mathrm{~mm}$ lateral, 4.5 $\mathrm{mm}$ ventral to bregma; Paxinos and Watson, 1998). Substances were infused using a $27 \mathrm{G}$ infusion cannula (Neumann et al., 2000). Lactating rats received the following: VEH $(0.5 \mu$ l of sterile Ringer's solution $+4 \%$ DMSO; pH 7.4; Braun), CRF-R1 agonist human/rat CRF (1 $\mu \mathrm{g} / 0.5 \mu \mathrm{l}$; Tocris Bioscience), CRF-R1 specific antagonist CP-154,526 (12 $\mu \mathrm{g} / 0.5$ $\mu \mathrm{l}$; Tocris Bioscience), CRF-R2 specific agonist hUcn 3 (stresscopin; 3 $\mu \mathrm{g} / 0.5 \mu \mathrm{l}$; Phoenix Pharmaceuticals), or CRF-R2 specific antagonist Astressin-2B ( $4 \mu \mathrm{g} / 0.5 \mu \mathrm{l}$; Sigma-Aldrich). Doses were chosen based on previous studies (Gammie et al., 2004; D’Anna et al., 2005; Sahuque et al., 2006; D'Anna and Gammie, 2009). To assess how far the drug diffused from the injection site, ink was infused (Pelikan ink 4001 diluted 1:20 in Ringer's solution) into the pBNST of three rats and the brains were collected for histological analysis. Because ink injected into the pBNST was also detected in the mBNST, we defined the treatment-affected region as the mpBNST. All rats were infused 30 min prior to testing. Assessment of behaviors on LD1, LD3, and LD5 were conducted as described in Behavioral tests, above. Importantly, the repeated acute infusion of the CRF-R1 or CRF-R2 agonist/antagonist separated by $48 \mathrm{~h}$ intervals and at the doses used here is not expected to result in receptor (de)sensitization (Prof. J. Radulovic, Northwestern University, personal communication; see also Spiess et al., 1998; Hauger et al., 2009). Moreover, in vitro studies have demonstrated rapid (within $1-2 \mathrm{~h}$ ) resensitization of the CRF-R after CRF-induced receptor internalization (Hauger et al., 2009). A different set of lactating dams was used for the PRT on LD2. All tests were performed between 8:00 A.M. and 3:00 P.M.

Experiment 4: Intra-mpBNST manipulation of CRF-R1 or CRF-R2 in virgin rats. Virgin rats underwent the same surgery as females in Experiment $3 \sim 2$ weeks after arrival. Starting $3 \mathrm{~d}$ after surgery, vaginal smears were taken to assess estrus cycle stage. Females in metestrus were tested the following day (i.e., presumed to be diestrus) on the EPM between 8:00 A.M. and 12:00 P.M. The females were placed on the EPM $10 \mathrm{~min}$ after intra-mpBNST manipulation with VEH, CP-154,526, or Astressin-2B (for details, see Experiment 3, above) to determine whether the effects of CRF-R manipulation on anxiety in lactating rats are sex or lactation specific, because anxiety-related behavior of male rats is seemingly modulated only by CRF-R1 manipulation (Sahuque et al., 2006). After the test, estrus cycle stage was verified via a vaginal smear and virgin rats not in diestrus were omitted from the data analysis.

Experiment 5: Intra-mpBNST manipulation of CRF-R1 or CRF-R2 in male rats. Recently, the effects of CRF-R manipulation in the BNST on male anxiety were reported (Sahuque et al., 2006). Because numerous subdivisions of the BNST were manipulated at the same time in that study, here, we focused exclusively on the mpBNST to assess clearly a potential sexual dimorphic effect of CRF in regulating anxiety in this subdivision of the BNST. Therefore, male rats were implanted bilaterally with cannula targeting the pBNST $\sim 2$ weeks after arrival at our animal facility (for details, see Experiment 3 ). Six days after surgery, the males were administered VEH, CRF, or stresscopin into the mpBNST (for details, see Experiment 3) and were placed $10 \mathrm{~min}$ (VEH, CRF) or $25 \mathrm{~min}$ (stresscopin) after infusion on the EPM. Two days later, the males were placed in the LDB after infusion with the same treatments as assigned for the EPM. In a different set of animals, we tested whether the application of CRF-R antagonists per se has anxiolytic effects, as was shown for females (see Experiment 3 and 4). Therefore, males were placed on the EPM 10 min after intra-mpBNST manipulation with VEH, CP-154,526, or Astressin-2B (for details, see Experiment 3 ) using the same doses as for virgin and lactating females.

\section{Histology}

At the end of the behavioral experiments, rats were decapitated. For intracerebroventricular cannula verification, brains were infused with blue ink, removed, and cut with a razor blade at the infusion site. Blue-colored ventricles indicated correct placement of the intracerebroventricular cannula (Experiment 1). To verify the correct placements of local cannula within the mpBNST, brains were removed, flash frozen, cut into $40 \mu \mathrm{m}$ coronal sections, slide mounted, and stained via quick Nissl staining (Experiments 3-5).

In situ hybridization for $C R F-R$ mRNA expression

Brains were sectioned at $16 \mu \mathrm{m}$ using a cryostat (CM3050S; Leica), slide mounted, and stored at $-20^{\circ} \mathrm{C}$ until further processing.

CRF-R1/2 mRNA in situ hybridization was conducted following an established protocol and using previously described riboprobes for CRF-R1 or CRF-R2 (Brunton et al., 2009; Brunton et al., 2011) kindly provided by Dr. Nicholas Justice (Salk Institute, La Jolla, CA). Some extra slides were also hybridized with ${ }^{35} \mathrm{~S}$-UTP-labeled cRNA sense probes to serve as negative controls. Autoradiograms of the mBNST (bregma $-0.2 \mathrm{~mm}$ to $-0.4 \mathrm{~mm}$ ) and the pBNST (bregma $-0.4 \mathrm{~mm}$ to $-0.9 \mathrm{~mm}$; Paxinos and Watson, 1998) were examined with Image J version 1.46 by an experienced observer blinded to the groups, as described previously (Brunton et al., 2011). In addition, all pictures were converted to 8 bit and their contrast was enhanced to the same extent. Measurements were made bilaterally over 6 sections per rat. Brain sections hybridized with ${ }^{35} \mathrm{~S}$-UTP-labeled cRNA sense probes showed no signal above background.

\section{Statistical analysis}

In situ hybridization data were analyzed using a two-way ANOVA (factors: reproductive status $\times$ brain site). For the behavioral studies, only animals that had been fitted correctly with the local cannula were included in the analysis. Behavioral data were analyzed using either oneway ANOVA (factor: treatment) or ANOVA for repeated measures (factors: time $\times$ treatment). One-way ANOVA was followed by SIDAK and ANOVA for repeated measures by Fisher's LSD post hoc test. For all tests, the software package SPSS 19.0 was used. Data are presented as means \pm SEM and significance was accepted at $p \leq 0.05$.

\section{Results}

\section{Experiment 1: Behavioral effects of nonspecific} intracerebroventricular manipulation of CRF-R1/2 in lactating rats

Maternal care under nonstress conditions on LD1

$A B N$. Neither significant differences depending on time and/or treatment nor an interaction were revealed by two-way ANOVA for repeated measures (Fig. $1 A$, top).

Nursing. Differences in nursing, which comprises all nursing positions, were found depending on treatment (two-way ANOVA for repeated measures; $F_{(2,16)}=4.17, p=0.03$ ), but not on time. However, there was a significant time $\times$ treatment interaction $\left(F_{(8,64)}=2.20, p=0.03\right.$; Fig. $1 A$, bottom $)$. No group differences were detected before treatment infusion. The infusion procedure decreased the occurrence of nursing in VEH-treated dams significantly $(p=0.01)$ and there was a tendency for a reduction in the CRF-R1/2-agonist-treated dams $(p=0.07)$ at $t$ $+30 \mathrm{~min}$. The CRF-R1/2 antagonist prevented this infusioninduced decrease at $t+30 \mathrm{~min}(p=0.01)$ while the agonist even prolonged the impairing effect on nursing at $t+90 \mathrm{~min}(p=$ $0.01)$ compared with VEH. In the afternoon, the occurrence of nursing did not differ between the groups (data not shown). 


\section{A maternal care} - non-stress conditions
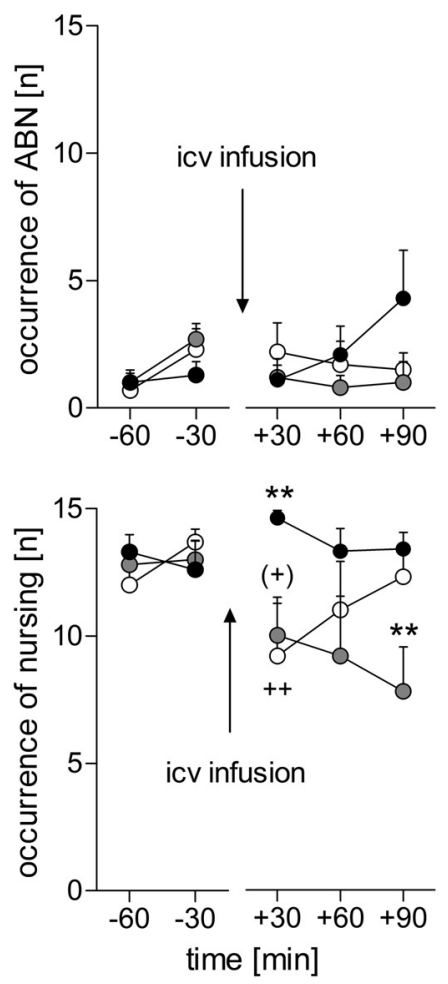

B maternal care - stress conditions
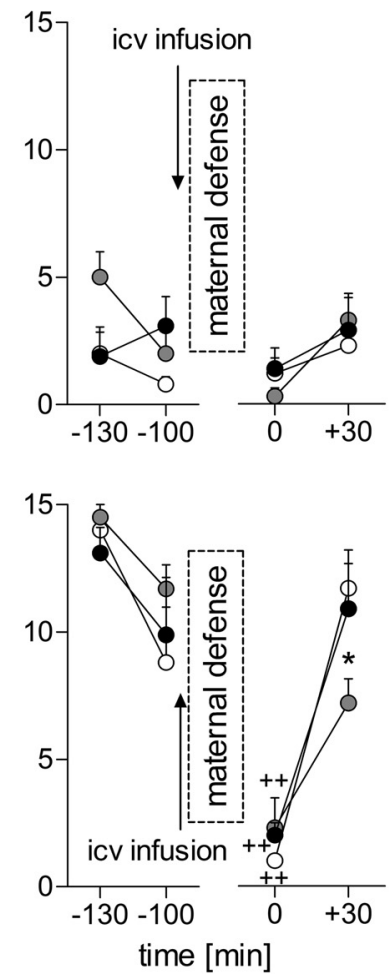

C maternal aggression
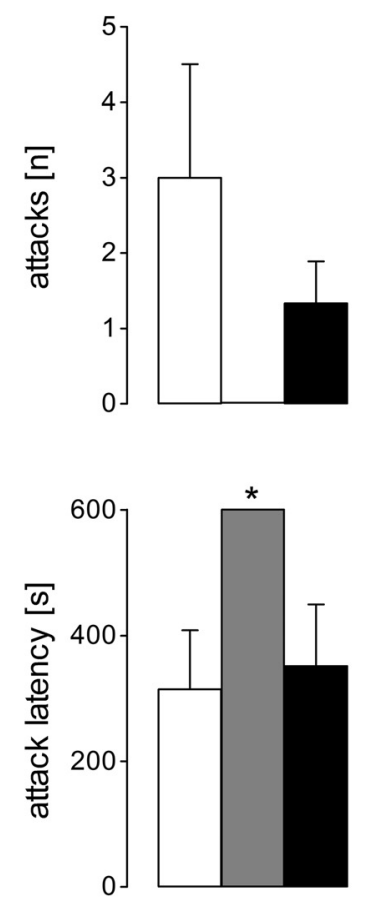

VEH

\section{D anxiety}
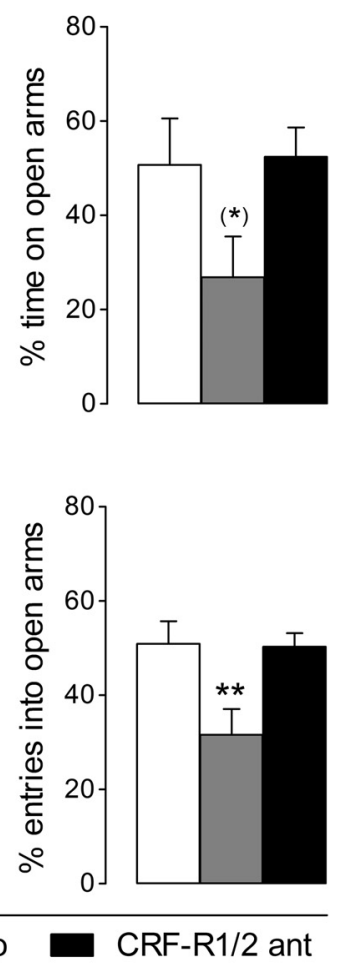

Figure 1. Effect of nonspecific intracerebroventricular CRF-R1/2 manipulation on maternal care under nonstress conditions on LD1 (A) and stress conditions on LD5 ( $B$ ), on maternal aggression during the maternal defense test on LD5 (C), and on anxiety-related behavior of lactating rats on $\operatorname{LD}(\boldsymbol{D})$. ABN $(\boldsymbol{A}, \boldsymbol{B}$, top) and sum of nursing $(\boldsymbol{A}, \boldsymbol{B}$, bottom) were scored for 60 min before and for 90 min after infusion $(\boldsymbol{A})$ or $60 \mathrm{~min}$ after maternal defense $(\boldsymbol{B})$. Maternal aggression was scored as number of attacks $(\boldsymbol{C}$, top) and attack latency $(\boldsymbol{C}$, bottom) by the resident. Anxiety-related behavior was measured as the percentage of time spent on the open arms ( $\boldsymbol{D}$, top) and the percentage of entries into the open arms ( $\boldsymbol{D}$, bottom) on the EPM. Dams received an acute intracerebroventricular infusion of VEH ( $5 \mu$ l of sterile Ringer's solution, pH 7.4), CRF-R1/2 agonist Ucn 1 (CRF-R1/2 ago; $1 \mu \mathrm{g} / 5 \mu \mathrm{l})$, or (RF-R1/2 antagonist D-Phe (CRF-R1/2 ant; $10 \mu \mathrm{g} / 5 \mu \mathrm{l})$. Data are presented as mean + SEM. $n=6-7$ per group. $\left.{ }^{* *} p \leq 0.01,{ }^{*} p \leq 0.05,{ }^{*}\right) p=0.06$ versus VEH; $++p \leq 0.01,(+) p=0.07$ versus previous time point (two-way ANOVA for repeated measures; factors: time $\times$ treatment).

Table 1. Effects of nonspecific icv CRF-R manipulation on nonmaternal behaviors under nonstress conditions on LD 1

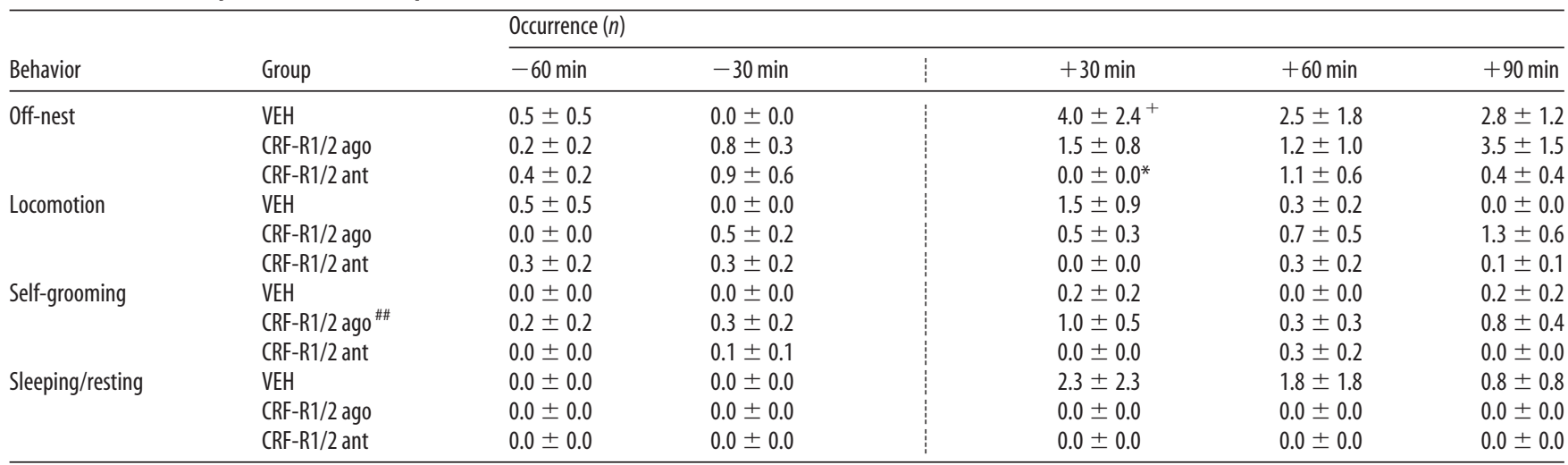

ago, Agonist; ant, antagonist.

The occurrence of all off-nest behaviors was scored for $60 \mathrm{~min}$ before and for $90 \mathrm{~min}$ after infusion (indicated by the dotted line). 0 off-nest behavior is further divided into locomotion (including digging/burrowing and any explorative behavio in the home cage), self-grooming, and sleeping/resting. For details on treatments, see legend to Figure 1. Data are presented as mean \pm SEM. $n=6-7$ per group. ${ }^{*} p \leq 0.05$ versus VEH; $+p \leq 0.05$ versus previous time point (two-way ANOVA for repeated measures; factors: time $\times$ treatment); \#\#p $\leq 0.01$ versus VEH (two-way ANOVA for repeated measures; factor: treatment).

Other maternal behaviors. No significant differences or interactions depending on time and/or treatment were found in licking/grooming and pup retrieval/mouthing (data not shown). We did not observe any pup killing following any of the treatments.

Nonmaternal behaviors. A significant interaction was found in the occurrence of off-nest behavior (two-way ANOVA for repeated measures; $F_{(8,68)}=2.20, p=0.03$; Table 1$)$. No differences were found depending on time or treatment. VEH-treated dams showed off-nest behavior more frequently at $t+30$ min compared with before infusion $(p=0.01)$ and with CRF-R1/2antagonist-treated dams $(p=0.04)$. CRF-R1/2-agonist-treated dams showed differences in self-grooming depending on treatment $\left(F_{(2,17)}=10.27, p<0.01\right)$, but not on time. No interaction was detected between the two factors. These dams showed significantly more self-grooming than VEH-treated dams $(p<0.01)$. No differences were detected for locomotion and sleeping/resting. 
Table 2. Effects of nonspecific icv CRF-R manipulation on nonmaternal behaviors under stress conditions on LD 5

\begin{tabular}{|c|c|c|c|c|c|}
\hline \multirow[b]{2}{*}{ Behavior } & \multirow[b]{2}{*}{ Group } & \multicolumn{4}{|c|}{ Occurrence $(n)$} \\
\hline & & $-130 \mathrm{~min}$ & $-100 \min$ & $0 \min$ & $+30 \min$ \\
\hline \multirow[t]{3}{*}{ Off-nest } & VEH & $0.0 \pm 0.0$ & $1.7 \pm 1.3$ & $8.5 \pm 1.7$ & $2.2 \pm 1.3$ \\
\hline & CRF-R1/2 ago & $0.3 \pm 0.3$ & $1.5 \pm 0.6$ & $10.0 \pm 1.5$ & $5.2 \pm 1.8$ \\
\hline & CRF-R1/2 ant & $0.9 \pm 0.4$ & $2.8 \pm 1.2$ & $8.5 \pm 1.3$ & $4.6 \pm 2.0$ \\
\hline \multirow[t]{3}{*}{ Locomotion } & VEH & $0.0 \pm 0.0$ & $1.0 \pm 0.7$ & $5.5 \pm 1.3$ & $0.2 \pm 0.2$ \\
\hline & CRF-R1/2 ago & $0.0 \pm 0.0$ & $0.3 \pm 0.2$ & $4.3 \pm 1.0$ & $0.7 \pm 0.2$ \\
\hline & CRF-R1/2 ant & $0.4 \pm 0.3$ & $0.9 \pm 0.6$ & $3.8 \pm 0.6$ & $0.8 \pm 0.4$ \\
\hline \multirow[t]{3}{*}{ Self-grooming } & VEH & $0.0 \pm 0.0$ & $0.0 \pm 0.0$ & $0.8 \pm 0.4$ & $0.3 \pm 0.3$ \\
\hline & CRF-R1/2 ago & $0.2 \pm 0.2$ & $0.2 \pm 0.2$ & $2.8 \pm 0.7^{* *++}$ & $0.5 \pm 0.3$ \\
\hline & CRF-R1/2 ant & $0.4 \pm 0.3$ & $0.5 \pm 0.3$ & $0.5 \pm 0.3$ & $0.5 \pm 0.3$ \\
\hline \multirow[t]{3}{*}{ Sleeping/resting } & VEH & $0.0 \pm 0.0$ & $0.0 \pm 0.0$ & $0.0 \pm 0.0$ & $1.0 \pm 0.6$ \\
\hline & CRF-R1/2 ago & $0.2 \pm 0.2$ & $0.3 \pm 0.3$ & $0.5 \pm 0.3$ & $2.7 \pm 1.7$ \\
\hline & CRF-R1/2 ant & $0.0 \pm 0.0$ & $0.3 \pm 0.3$ & $1.3 \pm 0.9$ & $2.6 \pm 1.7$ \\
\hline
\end{tabular}

ago, Agonist; ant, antagonist.

The occurrence of all off-nest behaviors was scored for $60 \mathrm{~min}$ before and for $60 \mathrm{~min}$ after the combined infusion with the maternal defense test (indicated by the dotted line). Off-nest behavior is further divided into locomotion (including digging/burrowing and any explorative behavior in the home cage), self-grooming, and sleeping/resting. For details on treatments, see legend to Figure 1 . Data are presented as mean \pm SEM. $n=6-7$ per group. ${ }^{* *} p \leq 0.01$ versus VEH; $++p \leq 0.01$ versus previous time point (two-way ANOVA for repeated measures; factors: time $\times$ treatment)

Maternal care under stress conditions on LD5

$A B N$. Differences in $A B N$ were found depending on time (ANOVA for repeated measures; $F_{(3,48)}=6.32, p<0.01$; Fig. $1 B$, top), but not on treatment. No interaction was found between the two factors.

Nursing. Differences in nursing were found depending on time (two-way ANOVA for repeated measures; $F_{(3,48)}=46.09$, $p<0.01$; Fig. $1 B$, bottom), but not on treatment. No interaction effect was found between the two factors. However, analysis of the within-subject contrasts revealed a significant linear interaction between the treatment groups at various time points (twoway ANOVA for repeated measures, $\left.F_{(2,16)}=4.09, p=0.03\right)$. In all three groups, nursing was decreased at $t 0$ min compared with all other intervals (VEH: $p<0.01$, in each case; CRF-R1/2 agonist: $t-130 \mathrm{~min} / t-100 \mathrm{~min}: p<0.01, t+30 \mathrm{~min}: p=0.04$; CRF-R1/2 antagonist: $p<0.01$, in each case). Furthermore, CRF$\mathrm{R} 1 / 2$ agonist-treated dams showed less nursing at $t+30 \mathrm{~min}$ compared with VEH-treated mothers $(p=0.05)$.

Other maternal behaviors. No significant differences or interactions depending on time and/or treatment were found in pup retrieval/mouthing and licking/grooming (data not shown). We did not observe any pup killing after any of the treatments.

Nonmaternal behaviors. All dams showed differences in the occurrence of off-nest behavior (two-way ANOVA for repeated measures; $\left.F_{(3,51)}=30.92, p<0.01\right)$, in locomotion $\left(F_{(3,51)}=\right.$ $50.14, p<0.01)$, and in sleeping/resting $\left(F_{(3,51)}=4.54, p<0.01\right)$ depending on time but not on treatment (Table 2). No interactions between the two factors were detected. Significant interactions were found in self-grooming $\left(F_{(6,51)}=4.48, p<0.01\right)$, which also differed depending on time $\left(F_{(3,51)}=9.91, p<0.01\right)$ and treatment $\left(F_{(2,17)}=3.64, p=0.04\right)$. CRF-R1/2-agonisttreated dams showed more self-grooming at $t 0$ min compared with the previous time point and compared with VEH-treated dams $(p<0.01$ in each case).

\section{Maternal motivation on LD2}

In the PRT, a strong trend toward reduced pup retrieval in CRFR1/2-agonist-treated dams was observed (VEH: $3.3 \pm 1.5$; Ucn: $0.4 \pm 0.3$; D-Phe: $3.5 \pm 0.8$ number of pups collected in $15 \mathrm{~min}$; one-way ANOVA; $\left.F_{(2,18)}=3.23, p=0.06\right)$. No differences were observed in CRF-R1/2-antagonist-treated dams.

\section{Maternal aggression on LD5}

The number of attacks did not differ between the groups even though CRF-R1/2 agonist injection completely abolished mater- nal aggression (Fig. 1C, top). However, the latency to the first attack was significantly affected by the treatment (one-way ANOVA; $F_{(2,15)}=3.93, p=0.04$; Fig. $1 C$, bottom). The CRF$\mathrm{R} 1 / 2$ agonist significantly increased the attack latency compared with VEH ( $p=0.05$ ). No other behavioral parameter (e.g., keep down, lateral threat, offensive upright) measured during the maternal defense test differed between the groups.

\section{Anxiety-related behavior on $L D 3$}

The treatment tended to alter the percentage of time spent on the open arms of the EPM (one-way ANOVA; $F_{(2,16)}=3.23, p=$ 0.06 ; Fig. $1 D$, top), whereas the percentage of open arm entries was significantly altered by the treatment $\left(F_{(2,16)}=6.43, p<0.01\right.$; Fig. $1 D$, bottom). CRF-R1/2-agonist-infused dams made significantly fewer entries into the open arms compared with VEH ( $p=$ 0.02; Fig. $1 D$, bottom). Importantly, entries into closed arms did not differ between the groups, indicating that the intracerebroventricular infusion did not affect locomotor activity (data not shown).

\section{Experiment 2: Expression of CRF-R1 and CRF-R2 mRNA in the BNST of virgin versus lactating rats}

CRF-R1 mRNA expression did not differ between virgin and lactating rats in either the mBNST or the pBNST (Fig. 2). CRF-R2 mRNA expression was higher in the pBNST compared with the mBNST (two-way ANOVA; factor: brain site; $F_{(1,19)}=12.05, p<$ 0.01 ; Fig. 2), but was not altered by the reproductive status nor was an interaction found between the two factors. There was no significant difference in the ratio of CRF-R1:R2 mRNA expression in either the mBNST (virgin $=9.5 \pm 3.1$; lactating $=8.9 \pm$ 1.5 ) or the pBNST (virgin $=2.7 \pm 0.5$; lactating $=2.8 \pm 0.1$ ) between virgin and lactating rats.

\section{Experiment 3: Behavioral effects of intra-mpBNST CRF-R1 or CRF-R2 manipulation in lactating rats}

The precise cannula placement sites within the mpBNST are illustrated in Figure $3 A$. The slow infusion of $0.5 \mu \mathrm{l}$ spreads out over an area of $1 \mathrm{~mm}^{3}$, thus mainly affecting the pBNST, but also the mBNST (Fig. 3B), which is consistent with previous findings (Engelmann et al., 1999).

Maternal care under nonstress conditions on LD1

$A B N$. Differences in $A B N$ were found depending on treatment (two-way ANOVA for repeated measures; $F_{(4,48)}=3.33, p=$ 


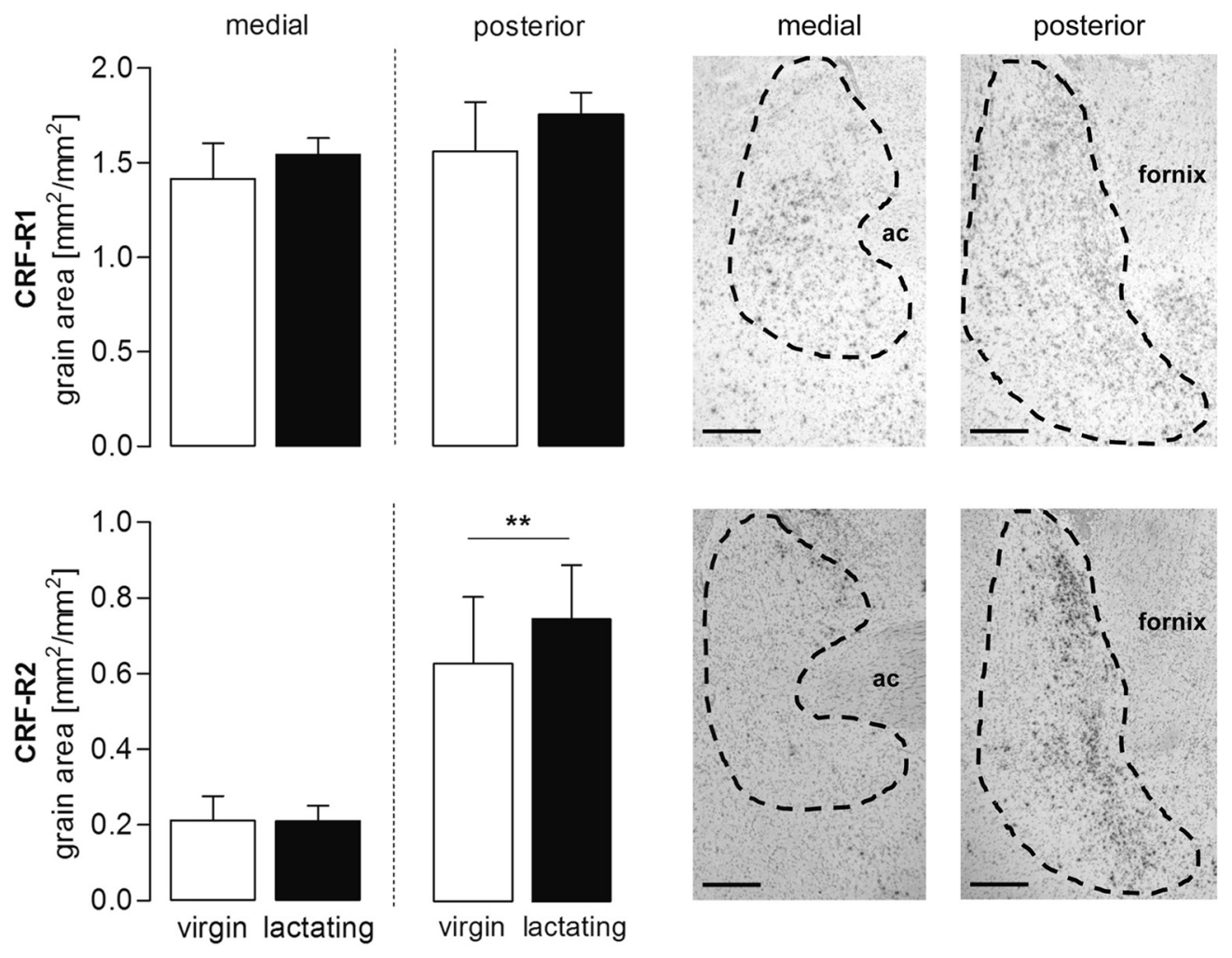

Figure 2. CRF-R1 (top) and CRF-R2 (bottom) mRNA expression in the medial and posterior part of the BNST comparing virgin and lactating rats. Data are presented as mean grain area + SEM. $n=4-7$ per group. ${ }^{* *} p \leq 0.01$ versus medial part (two-way ANOVA; factors: reproductive status $\times$ brain site). Representative photomicrographs from a lactating rat are shown on the right side (4X objective) Scale bar, $500 \mu \mathrm{m}$. Hybridization is evident as localized clumps of silver grains. ac, Anterior commissure.

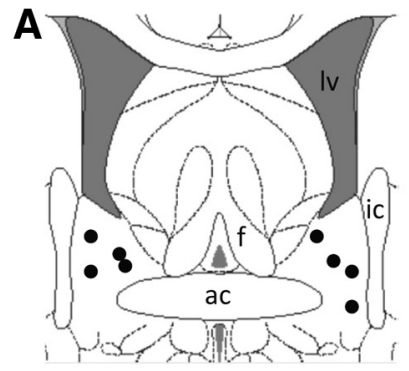

bregma $-0.36 \mathrm{~mm}$

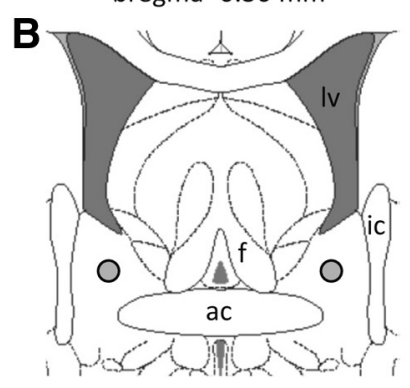

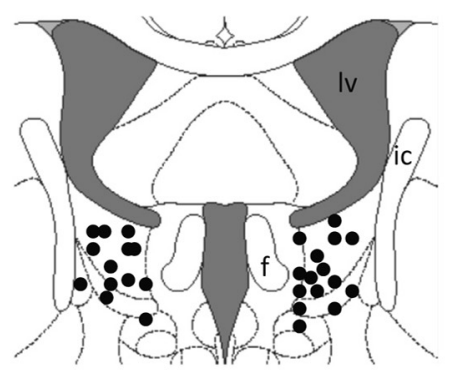

bregma $-0.60 \mathrm{~mm}$

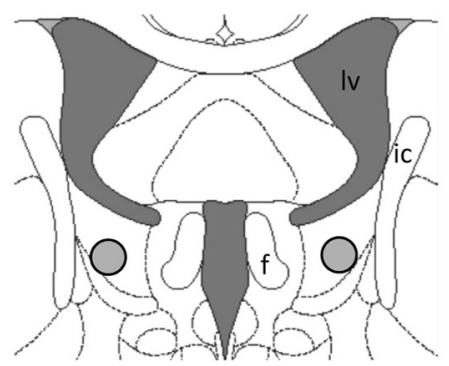

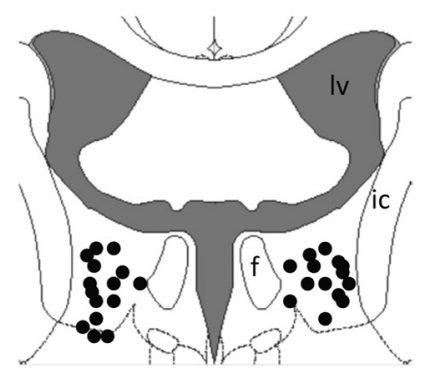

bregma $-0.70 \mathrm{~mm}$

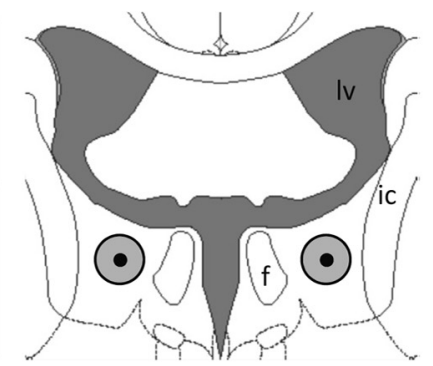

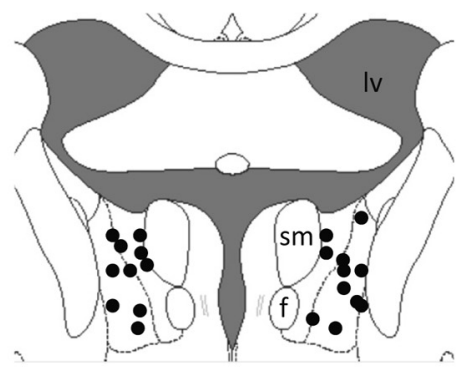

bregma $-0.96 \mathrm{~mm}$

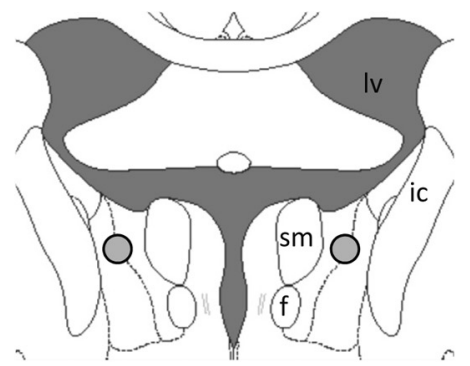

Figure 3. Histological localization of infusion cannula within the mpBNST. $A$, Cannula placement sites for subsequent drug infusion are shown as black dots within the mpBNST on schematic plates from the Paxinos and Watson (1998) stereotaxic atlas. $\boldsymbol{B}$, Extent of substance spreading after ink infusion (black dot) in three rats is shown schematically as gray circles within the mpBNST. ac, Anterior commissure; f, fornix; ic, internal capsule; Iv, lateral ventricle; sm, stria medullaris of the thalamus.

$0.01)$, but not on time. However, there was a significant time $\times$ treatment interaction $\left(F_{(24,288)}=1.57, p=0.04\right.$; Fig. $4 A$, top $)$. Before the infusion, no differences were detected between the groups. Shortly afterward, dams treated with the CRF-R1 agonist showed less $\mathrm{ABN}$ at $t+30 \mathrm{~min}$ and $t+60 \mathrm{~min}(p=0.03$ in each case) compared with VEH-treated dams. During the observation in the afternoon, less ABN was observed in CRF-R1-antagonist-treated dams at $t+300$ min and in CRF-R2-agonist-treated dams at $t+300$ min and $t+330$ min compared with VEH ( $p<0.01$ in each case).

Nursing. Differences in nursing were found depending on time (two-way ANOVA for repeated measures; $F_{(6,24)}=2.85, p=$ $0.01)$ and on treatment $\left(F_{(4,48)}=4.24, p<0.01\right)$. Moreover, a 


\section{-o- CRF-R1 ago $\triangle-$ CRF-R1 ant \\ -O- VEH}

A non-stress conditions

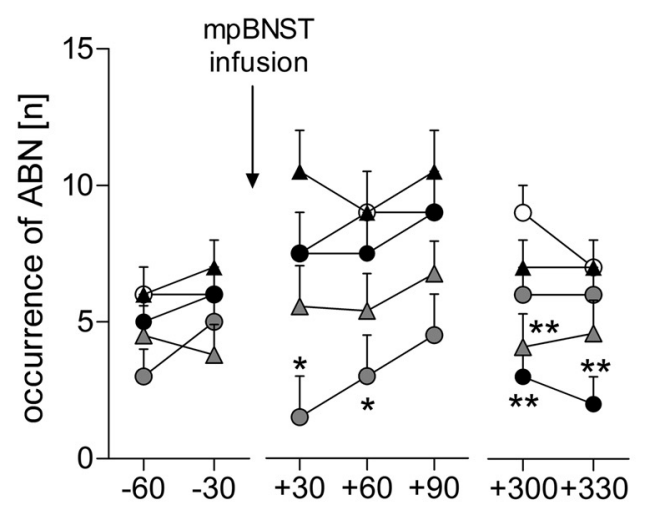

B stress conditions

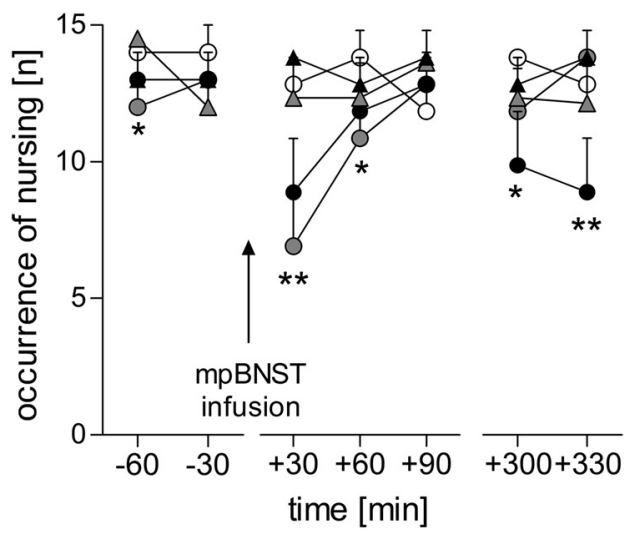

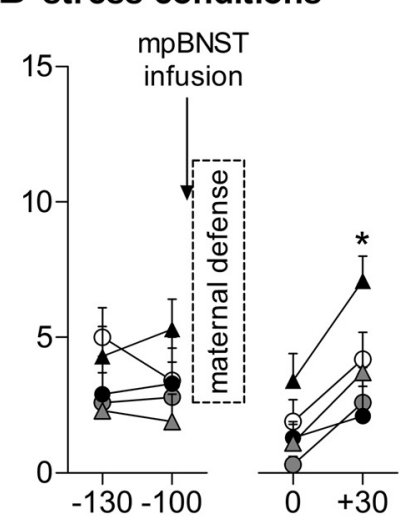

$\rightarrow$ CRF-R2 ago

$\mp$ CRF-R2 ant

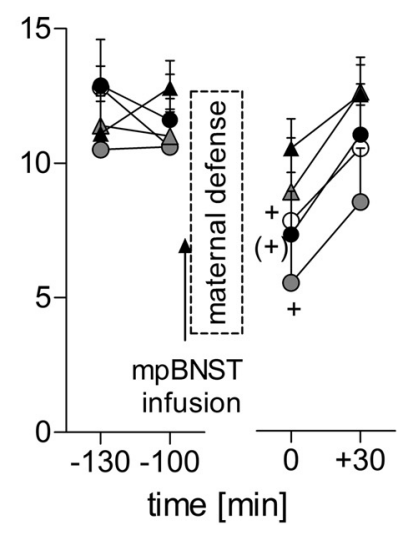

Figure 4. Effect of intra-mpBNST CRF-R1 or CRF-R2 specific agonist (ago) or antagonist (ant) treatment on maternal care of lactating dams under nonstress conditions on LD1 $(\boldsymbol{A})$ and stress conditions on LD5 (B). ABN (top) and sum of nursing (bottom) were scored for $60 \mathrm{~min}$ before and for $90 \mathrm{~min}$ after infusion $(\boldsymbol{A})$ or $60 \mathrm{~min}$ after maternal defense $(\boldsymbol{B})$. Under nonstress conditions, $A B N$ and nursing were also observed for additional 60 min in the afternoon $(A)$. Dams received an acute bilateral infusion of VEH (5 $\mu$ l of sterile Ringer's solution; pH 7.4), CRF-R1 agonist human/rat CRF (CRF-R1 ago; $1 \mu \mathrm{g} / 0.5 \mu \mathrm{l}$ ), CRF-R1 antagonist (P-154,526 (CRF-R1 ant; $12 \mu \mathrm{g} / 0.5 \mu \mathrm{l}$ ), CRF-R2 agonist stresscopin (CRF-R2 ago; $3 \mu \mathrm{g} / 0.5 \mu \mathrm{l}$ ), or CRF-R2 antagonist Astressin-2B (CRF-R2 ant; $4 \mu \mathrm{g} / 0.5 \mu \mathrm{l}$ ) into the mpBNST. Data are presented as mean + SEM. $n=8-14$ per group. ${ }^{* *} p \leq 0.01,{ }^{*} p \leq 0.05$ versus VEH (two-way ANOVA for repeated measures; factors: time $\times$ treatment); $+p \leq 0.05,(+) p=0.08$ versus $t-100$ min (one-way ANOVA for repeated measures; factor: time).

significant time $\times$ treatment interaction was revealed $\left(F_{(24,288)}=\right.$ $1.69, p=0.02$; Fig. $4 A$, bottom). Before the infusion, no differences were found. Shortly afterward, the CRF-R1-agonist-treated dams showed less nursing at $t+30 \mathrm{~min}(p<0.01)$ and $t+60 \mathrm{~min}$ $(p=0.05)$ compared with VEH. During the observation in the afternoon, the CRF-R2 agonist resulted in significantly less nursing at $t+300 \mathrm{~min}(p=0.03)$ and $t+330 \mathrm{~min}(p<0.01)$ compared with $\mathrm{VEH}$.

Other maternal behaviors. No significant differences or interactions depending on time and/or treatment were found in pup retrieval/mouthing and licking/grooming (data not shown). We did not observe any pup killing after any of the treatments.

Nonmaternal behaviors. Significant interactions were found in the occurrence of off-nest behavior (two-way ANOVA for repeated measures; $F_{(24,288)}=1.62, p=0.03$; Table 3), which also differed depending on time $\left(F_{(6,288)}=3.14, p<0.01\right)$ and treatment $\left(F_{(4,48)}=3.20, p=0.02\right)$. CRF-R1- and CRF-R2-agonisttreated dams showed off-nest behavior more frequently compared with the respective previous time point $(p<0.01$ in each case) and compared with VEH at $t+30 \mathrm{~min}$ (CRF-R1 agonist: $p<0.01$, CRF-R2 agonist: $p=0.01$ ). In addition, CRF-R2-

agonist-treated dams displayed more offnest behaviors at $t+330 \min (p=0.01)$. Differences in locomotion were found depending on time $\left(F_{(6,288)}=8.05, p<\right.$ 0.01 ), but not on treatment. However, a significant interaction was detected $\left(F_{(24,288)}=2.78, p<0.01\right)$. CRF-R1agonist-treated dams showed more locomotion compared with the previous time point and compared with VEH at $t+30$ min $(p<0.01$ in each case). CRF-R2agonist-treated dams showed more locomotion at $t+330$ min compared with VEH $(p=0.05)$. Differences in selfgrooming were found depending on time $\left(F_{(6,288)}=8.56, p<0.01\right)$, but not on treatment. However, a significant interaction was detected $\left(F_{(24,288)}=3.15, p<\right.$ 0.01). CRF-R1 $(p<0.01)$ and CRF-R2agonist-treated dams $(p=0.02)$ showed more self-grooming at $t+30 \mathrm{~min}$ compared with the respective previous time point. In addition, CRF-R1-agonisttreated dams showed more selfgrooming at $t+30 \mathrm{~min}(p<0.01)$, as did CRF-R1-antagonist-treated dams at $t$ +330 min compared with VEH. CRF-R2antagonist-treated dams showed less selfgrooming at $t+90 \min (p=0.05)$. Differences in sleeping/resting were found depending on time $\left(F_{(6,288)}=4.72\right.$, $p<0.01)$ and treatment $\left(F_{(4,48)}=3.89\right.$, $p<0.01)$. However, no significant interaction was detected. CRF-R2-agonisttreated dams showed more sleeping/ resting at $t+30 \mathrm{~min}$ compared with the previous time point $(p<0.01)$ and at $t$ $+300 \mathrm{~min}(p=0.01)$ and $t+330 \mathrm{~min}$ $(p<0.01)$ compared with VEH.

Maternal care under stress conditions on LD5

$A B N$. Differences in $\mathrm{ABN}$ depending on time (two-way ANOVA for repeated measures; factor: time; $F_{(3,120)}=4.64, p<0.01$ ) and treatment (factor: treatment; $F_{(4,40)}$ $=4.17, p<0.01$ ) were detected (Fig. $4 B$, top); however, no interaction effect was found. Although no differences in $\mathrm{ABN}$ were found before any manipulation, the infusion paired with the maternal defense test led to a significant reduction in the occurrence of $\mathrm{ABN}$ in the $\mathrm{VEH}$ group $(t-100 \mathrm{~min}$ versus $t 0 \mathrm{~min} ; p=$ $0.01)$. Only the CRF-R2-antagonist-treated dams showed more $\mathrm{ABN}$ at $t+30 \mathrm{~min}(p=0.04)$ compared with the VEH-treated dams.

Nursing. Differences in nursing were found depending on time (ANOVA for repeated measures; $F_{(3,120)}=9.57, p<0.01$; Fig. $4 B$, bottom), but not on treatment, nor was an interaction effect detected. However, single analysis of the time courses within the different treatment groups revealed main effects in VEH-treated dams (one-way ANOVA for repeated measures; $\left.F_{(3,33)}=4.29, p=0.01\right)$ and CRF-R1-agonist-treated dams $\left(F_{(3,21)}=3.6, p=0.03\right)$, as well as a trend in CRF-R2 agonisttreated dams $\left(F_{(3,18)}=2.53, p=0.08\right)$. The occurrence of nursing was decreased at $t+30$ min compared with prestress levels (VEH: 
Table 3. Effects of specific intra-mpBNST CRF-R manipulation on nonmaternal behaviors under nonstress conditions on LD 1

\begin{tabular}{|c|c|c|c|c|c|c|c|c|c|}
\hline \multirow[b]{2}{*}{ Behavior } & \multirow[b]{2}{*}{ Group } & \multicolumn{8}{|c|}{ Occurrence $(n)$} \\
\hline & & $-60 \min$ & $-30 \mathrm{~min}$ & 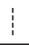 & $+30 \mathrm{~min}$ & $+60 \mathrm{~min}$ & $+90 \mathrm{~min}$ & $+300 \min$ & $+330 \min$ \\
\hline \multirow[t]{5}{*}{ Off-nest } & VEH & $0.4 \pm 0.1$ & $1.0 \pm 0.6$ & & $1.3 \pm 1.0$ & $0.9 \pm 0.7$ & $2.3 \pm 1.2$ & $0.3 \pm 0.2$ & $0.5 \pm 0.4$ \\
\hline & CRF-R1 ago & $1.1 \pm 0.7$ & $0.6 \pm 0.6$ & & $6.6 \pm 1.4^{* *++}$ & $1.4 \pm 0.5$ & $0.5 \pm 0.3$ & $1.9 \pm 1.7$ & $0.6 \pm 0.6$ \\
\hline & CRF-R1 ant & $0.0 \pm 0.0$ & $1.7 \pm 1.0$ & & $2.0 \pm 1.3$ & $1.7 \pm 1.3$ & $0.5 \pm 0.2$ & $1.7 \pm 1.2$ & $2.5 \pm 1.4$ \\
\hline & CRF-R2 ago & $1.4 \pm 0.6$ & $1.2 \pm 0.6$ & & $5.3 \pm 1.8^{*++}$ & $2.8 \pm 1.6$ & $1.9 \pm 0.9$ & $3.3 \pm 1.7$ & $4.8 \pm 2.2^{*}$ \\
\hline & CRF-R2 ant & $1.3 \pm 0.7$ & $0.7 \pm 0.4$ & & $0.5 \pm 0.2$ & $1.7 \pm 0.7$ & $1.2 \pm 0.9$ & $1.4 \pm 1.1$ & $0.2 \pm 0.2$ \\
\hline \multirow[t]{5}{*}{ Locomotion } & VEH & $0.3 \pm 0.1$ & $0.3 \pm 0.2$ & & $0.1 \pm 0.1$ & $0.0 \pm 0.0$ & $0.4 \pm 0.3$ & $0.2 \pm 0.1$ & $0.0 \pm 0.0$ \\
\hline & CRF-R1 ago & $0.5 \pm 0.4$ & $0.1 \pm 0.1$ & & $3.9 \pm 1.0^{* *++}$ & $1.0 \pm 0.3$ & $0.1 \pm 0.1$ & $0.1 \pm 0.1$ & $0.0 \pm 0.0$ \\
\hline & CRF-R1 ant & $0.0 \pm 0.0$ & $1.1 \pm 0.7$ & & $1.6 \pm 1.2$ & $1.0 \pm 0.7$ & $0.2 \pm 0.2$ & $0.3 \pm 0.1$ & $0.2 \pm 0.1$ \\
\hline & CRF-R2 ago & $0.4 \pm 0.2$ & $1.1 \pm 0.7$ & & $1.4 \pm 0.6$ & $0.8 \pm 0.4$ & $0.2 \pm 0.1$ & $0.1 \pm 0.1$ & $0.2 \pm 0.1^{*}$ \\
\hline & CRF-R2 ant & $0.4 \pm 0.2$ & $0.4 \pm 0.2$ & & $0.2 \pm 0.1$ & $0.5 \pm 0.3$ & $0.7 \pm 0.5$ & $0.0 \pm 0.0$ & $0.0 \pm 0.0$ \\
\hline \multirow[t]{5}{*}{ Self-grooming } & VEH & $0.1 \pm 0.1$ & $0.3 \pm 0.3$ & & $0.3 \pm 0.3$ & $0.3 \pm 0.2$ & $0.4 \pm 0.2$ & $0.2 \pm 0.2$ & $0.0 \pm 0.0$ \\
\hline & CRF-R1 ago & $0.1 \pm 0.1$ & $0.1 \pm 0.1$ & & $2.0 \pm 0.5^{* *++}$ & $0.4 \pm 0.3$ & $0.1 \pm 0.1$ & $0.1 \pm 0.1$ & $0.0 \pm 0.0$ \\
\hline & CRF-R1 ant & $0.0 \pm 0.0$ & $0.2 \pm 0.1$ & & $0.1 \pm 0.1$ & $0.2 \pm 0.2$ & $0.3 \pm 0.2$ & $0.1 \pm 0.1$ & $0.3 \pm 0.1^{*}$ \\
\hline & CRF-R2 ago & $0.2 \pm 0.1$ & $0.0 \pm 0.0$ & & $0.9 \pm 0.4^{+}$ & $0.3 \pm 0.2$ & $0.1 \pm 0.1$ & $0.1 \pm 0.1$ & $0.1 \pm 0.1$ \\
\hline & CRF-R2 ant & $0.2 \pm 0.2$ & $0.1 \pm 0.1$ & & $0.2 \pm 0.1$ & $0.2 \pm 0.2$ & $0.0 \pm 0.0^{*}$ & $0.1 \pm 0.1$ & $0.0 \pm 0.0$ \\
\hline \multirow[t]{5}{*}{ Sleeping/resting } & VEH & $0.0 \pm 0.0$ & $0.0 \pm 0.0$ & & $0.6 \pm 0.6$ & $0.0 \pm 0.0$ & $1.3 \pm 1.3$ & $0.0 \pm 0.0$ & $0.0 \pm 0.0$ \\
\hline & CRF-R1 ago & $0.0 \pm 0.0$ & $0.0 \pm 0.0$ & & $0.0 \pm 0.0$ & $0.0 \pm 0.0$ & $0.0 \pm 0.0$ & $1.6 \pm 1.6$ & $0.6 \pm 0.6$ \\
\hline & CRF-R1 ant & $0.0 \pm 0.0$ & $0.0 \pm 0.0$ & & $0.0 \pm 0.0$ & $0.0 \pm 0.0$ & $0.0 \pm 0.0$ & $1.4 \pm 1.1$ & $1.9 \pm 1.4$ \\
\hline & CRF-R2 ago & $0.0 \pm 0.0$ & $0.0 \pm 0.0$ & & $2.1 \pm 1.4^{++}$ & $1.4 \pm 1.4$ & $1.0 \pm 0.7$ & $4.7 \pm 2.1^{* *}$ & $4.4 \pm 2.2^{* *}$ \\
\hline & CRF-R2 ant & $0.0 \pm 0.0$ & $0.0 \pm 0.0$ & & $0.0 \pm 0.0$ & $0.0 \pm 0.0$ & $0.0 \pm 0.0$ & $1.2 \pm 1.1$ & $0.2 \pm 0.2$ \\
\hline
\end{tabular}

ago, Agonist; ant, antagonist.

The occurrence of all off-nest behaviors was scored for $60 \mathrm{~min}$ before and $90 \mathrm{~min}$ after infusion (indicated by the dotted line), as well as for 60 min in the afternoon (last 2 columns). Off-nest behavior is further divided into locomotion (including digging/burrowing and any explorative behavior in the home cage), self-grooming, and sleeping/resting. For details on treatments, see legend to Figure 4. Data are presented as mean \pm SEM. $n=8-14$ per group. ${ }^{* *} p \leq 0.01$, ${ }^{*} p \leq 0.05$ versus VEH; $++p \leq 0.01,+p \leq 0.05$ versus previous time point (two-way ANOVA for repeated measures; factors: time $\times$ treatment).

Table 4. Effects of specific intra-mpBNST CRF-R manipulation on nonmaternal behaviors under stress conditions on LD 5

\begin{tabular}{|c|c|c|c|c|c|c|}
\hline \multirow[b]{2}{*}{ Behavior } & \multirow[b]{2}{*}{ Group } & \multicolumn{5}{|c|}{ Occurrence $(n)$} \\
\hline & & $-130 \min$ & $-100 \min$ & 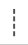 & $0 \min$ & $+30 \mathrm{~min}$ \\
\hline \multirow{5}{*}{ Off-nest } & VEH & $2.4 \pm 1.1$ & $4.1 \pm 1.5$ & & $6.3 \pm 1.7$ & $4.0 \pm 1.6$ \\
\hline & CRF-R1 ago & $3.9 \pm 2.2$ & $3.5 \pm 1.8$ & & $8.3 \pm 2.0$ & $4.9 \pm 2.0$ \\
\hline & CRF-R1 ant & $1.1 \pm 0.6$ & $3.1 \pm 0.8$ & & $5.4 \pm 2.0$ & $1.7 \pm 0.9$ \\
\hline & CRF-R2 ago & $1.6 \pm 1.3$ & $3.3 \pm 1.5$ & & $5.4 \pm 1.5$ & $2.7 \pm 1.6$ \\
\hline & CRF-R2 ant & $3.0 \pm 1.1$ & $1.7 \pm 0.7$ & & $3.8 \pm 1.2$ & $2.2 \pm 1.3$ \\
\hline \multirow{5}{*}{ Locomotion } & VEH & $0.2 \pm 0.1$ & $0.5 \pm 0.3$ & & $2.5 \pm 0.8$ & $0.7 \pm 0.3$ \\
\hline & CRF-R1 ago & $1.5 \pm 1.1$ & $0.8 \pm 0.5$ & & $4.6 \pm 1.4$ & $0.9 \pm 0.5$ \\
\hline & CRF-R1 ant & $0.3 \pm 0.2$ & $1.3 \pm 0.7$ & & $3.0 \pm 1.2$ & $1.1 \pm 0.6$ \\
\hline & CRF-R2 ago & $0.2 \pm 0.1$ & $1.7 \pm 0.9$ & & $1.7 \pm 0.4$ & $0.6 \pm 0.3$ \\
\hline & CRF-R2 ant & $1.3 \pm 0.5$ & $0.5 \pm 0.3$ & & $1.7 \pm 0.6$ & $0.5 \pm 0.2$ \\
\hline \multirow[t]{5}{*}{ Self-grooming } & VEH & $0.6 \pm 0.3$ & $1.0 \pm 0.6$ & & $1.7 \pm 0.5$ & $0.3 \pm 0.2$ \\
\hline & CRF-R1 ago & $0.1 \pm 0.1$ & $0.4 \pm 0.2$ & & $1.1 \pm 0.5$ & $1.0 \pm 0.4$ \\
\hline & CRF-R1 ant & $0.1 \pm 0.1$ & $0.7 \pm 0.4$ & & $2.0 \pm 1.6$ & $0.6 \pm 0.4$ \\
\hline & CRF-R2 ago & $0.1 \pm 0.1$ & $0.3 \pm 0.3$ & & $1.1 \pm 0.4$ & $0.0 \pm 0.0$ \\
\hline & CRF-R2 ant & $0.4 \pm 0.2$ & $0.5 \pm 0.5$ & & $0.7 \pm 0.3$ & $0.0 \pm 0.0$ \\
\hline \multirow[t]{5}{*}{ Sleeping/resting } & VEH & $0.3 \pm 0.3$ & $0.2 \pm 0.1$ & & $0.8 \pm 0.6$ & $2.4 \pm 1.6$ \\
\hline & CRF-R1 ago & $0.0 \pm 0.0$ & $1.6 \pm 1.6$ & & $1.3 \pm 1.1$ & $2.8 \pm 2.0$ \\
\hline & CRF-R1 ant & $0.1 \pm 0.1$ & $0.0 \pm 0.0$ & & $0.0 \pm 0.0$ & $0.0 \pm 0.0$ \\
\hline & CRF-R2 ago & $1.0 \pm 1.0$ & $0.4 \pm 0.4$ & & $1.4 \pm 1.1$ & $1.6 \pm 1.3$ \\
\hline & CRF-R2 ant & $0.0 \pm 0.0$ & $0.0 \pm 0.0$ & 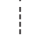 & $0.9 \pm 0.7$ & $1.2 \pm 1.2$ \\
\hline
\end{tabular}

ago, Agonist; ant, antagonist.

The occurrence of all off-nest behaviors was scored for $60 \mathrm{~min}$ before and $60 \mathrm{~min}$ after the combined infusion with the maternal defense test (indicated by the dotted line). Off-nest behavior is further divided into locomotion (including digging/burrowing and any explorative behavior in the home cage), self-grooming, and sleeping/resting. For details on treatments, see legend to Figure 4 . Data are presented as mean \pm SEM. $n=8-14$ per group.

$t 0 \min$ vs $t-130 \min : p=0.01, t 0 \min$ vs $t-100 \min : p=0.06$ CRF: $t 0$ min vs $t-130 \mathrm{~min}: p=0.03, t 0 \mathrm{~min}$ vs $t-100 \mathrm{~min}: p=$ 0.05). Treatment with either the CRF-R1 or CRF-R2 antagonist prevented this stress-induced reduction in nursing.

Other maternal behaviors. No significant differences or interactions depending on time and/or treatment were found in pup retrieval/mouthing and licking/grooming (data not shown). We did not observe any pup killing after any of the treatments.

Nonmaternal behaviors. Dams differed in the occurrence of off-nest behavior $\left(F_{(3,126)}=8.59, p<0.01\right.$; Table 4$)$, selfgrooming $\left(F_{(3,126)}=7.33, p<0.01\right)$, and locomotion $\left(F_{(3,126)}=\right.$ 16.52, $p<0.01)$ depending on time. However, no treatment or interaction effects were observed. For locomotion, a strong trend for an interaction was detected $\left(F_{(12,126)}=1.76, p=0.06\right)$. No differences were found in sleeping/resting.

Maternal motivation on LD2

None of the treatments affected pup retrieval behavior (pups retrieved within $15 \mathrm{~min}: \mathrm{VEH}$ : $7.3 \pm 0.5$; CRF-R1 agonist: $7.0 \pm$ 1.0; CRF-R1 antagonist: $8.0 \pm 0.0$; CRF-R2 agonist: $5.3 \pm 2.7$; CRF-R2 antagonist: $2.8 \pm 1.5)$.

Maternal aggression on LD5

The number of attacks (one-way ANOVA; $F_{(4,39)}=5.53, p=$ 0.01 ; Fig. 5, left $)$ and the attack latency $\left(F_{(4,39)}=10.16, p<0.01\right.$; 


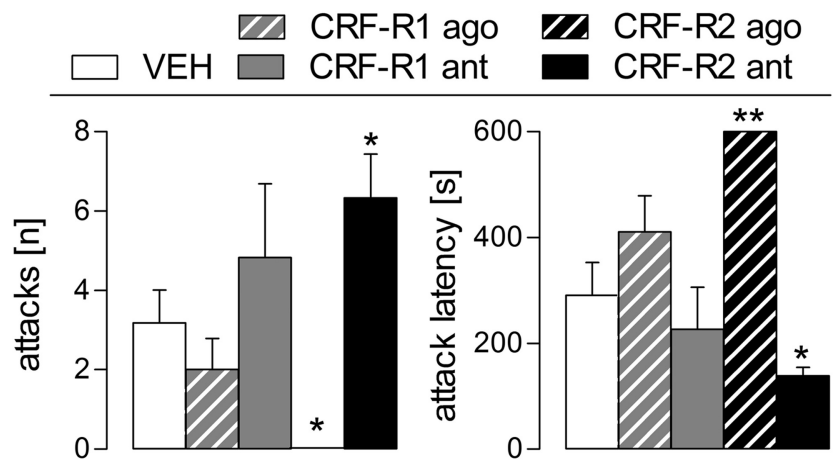

Figure 5. Effect of intra-mpBNST CRF-R1 or CRF-R2 specific agonist (ago) or antagonist (ant) treatment on maternal aggression of lactating rats measured in the maternal defense test. Maternal aggression against a virgin female intruder was scored during the $10 \mathrm{~min}$ trial. Number of attacks (left) and attack latency (right) by the resident is shown. For details on treatments, see legend to Figure 4 . Data are presented as mean + SEM. $n=7-11$ per group. ${ }^{* *} p \leq$ $0.01,{ }^{*} p \leq 0.05$ versus VEH (one-way ANOVA; factor: treatment).

Fig. 5, right) differed between the groups. The CRF-R2 agonist completely blocked attacks $(p=0.02)$ and thus increased the attack latency $(p<0.01)$ compared with the VEH-treated dams. Accordingly, the CRF-R2 antagonist increased the number of attacks $(p=0.02)$ and decreased the attack latency $(p=0.03)$. Neither the CRF-R1 agonist nor antagonist had any significant effect on maternal aggression. No other behavioral parameters (e.g., keep down, lateral threat, offensive upright) measured during maternal defense differed between the groups.

\section{Anxiety-related behavior on LD3}

Treatment significantly altered the percentage of time spent on the open arms of the EPM in the lactating dams (one-way ANOVA; $F_{(4,43)}=16.21, p<0.01$; Fig. 6, left). Mothers treated with the CRF-R1 agonist spent significantly less time in the open arms $(p=0.04)$, whereas dams injected with the antagonist for CRF-R1 $(p<0.01)$ or CRF-R2 $(p<0.01)$ spent significantly more time on the open arms compared with the VEH-treated dams. CRF-R2-agonist-infused mothers did not significantly differ from VEH-treated mothers. Regarding locomotor activity, no group differences were detected in number of entries into the closed arms (data not shown).

\section{Experiments 4 and 5: Behavioral effects of intra-mpBNST CRF-R1 or CRF-R2 blockade on anxiety in virgin and male rats}

Virgin rats

The percentage of time spent on the open arms of the EPM significantly differed depending on the treatment (one-way ANOVA; $F_{(2,11)}=7.03, p=0.01$; Fig. $6 A$ ). Females treated with the CRF-R1 antagonist $(p=0.03)$ or the CRF-R2 antagonist $(p<0.01)$ spent significantly more time on the open arms compared with the VEH-treated females. No difference was found in the number of closed arm entries between any of the groups (data not shown).

\section{Male rats}

No statistically significant differences were found in any of the parameters tested in male rats either on the EPM or in the LDB when infused with subtype-specific CRF-R agonists or antagonists (Fig. 6B).

\section{Discussion}

This is the first study to provide evidence that CRF-R2 and, to a lesser extent, CRF-R1 in the mpBNST are important in regulating maternal behavior in lactating rats. CRF-R2, but not CRF-R1, mRNA expression was higher in the pBNST versus mBNST independently of reproductive status (Fig. 2). The behavioral experiments revealed that $\mathrm{ABN}$ and total nursing were rapidly impaired by intra-mpBNST CRF-R1 agonist and after a delay by the CRF-R2 agonist. However, under stress conditions, ABN was increased only by the CRF-R2 antagonist, whereas both antagonists prevented the typical decrease in nursing after stress (Fig. 4). During the maternal defense test, the CRF-R2 agonist abolished maternal aggression, whereas the CRF-R2 antagonist increased aggression; however, CRF-R1 manipulation had no significant effect (Fig. 5). Furthermore, the CRF-R1 agonist increased, whereas both antagonists decreased, anxiety-related behavior in virgin and lactating rats, but not in male rats (Fig. 6).

Several studies suggest a crucial contribution of CRF in regulating cellular (Lightman et al., 2001; Walker et al., 2001; da Costa et al., 2001; Deschamps et al., 2003) and behavioral adaptations (Pedersen et al., 1991; Gammie et al., 2004; Klampfl et al., 2013) in lactating females. We demonstrated recently that activation of central CRF-R1/2 reduces, and their blockade increases, maternal behavior, whereas anxiety was altered conversely (Klampfl et al., 2013). Because the previously infused agonist CRF binds with 40-fold higher affinity to CRF-R1 (Hauger et al., 2003), it is often used as a CRF-R1-specific agonist (e.g., Magalhaes et al., 2010). Therefore, we aimed to confirm our earlier results using the nonspecific CRF-R1/2 agonist Ucn 1 (Fig. 1). Importantly, the behavioral effects were similar to our recent data (Klampfl et al., 2013) and also support previous studies demonstrating a detrimental effect of CRF-R activation on maternal behavior (Pedersen et al., 1991; Gammie et al., 2004; Klampfl et al., 2013). Consistent with our findings in rats, intracerebroventricular Ucn 1 impairs maternal aggressive behavior in lactating mice (D'Anna et al., 2005). Furthermore, Ucn 1 is known to be anxiogenic in male rodents (Moreau et al., 1997; Spina et al., 2002), which we now extend to lactating rats (Fig. 1). These results confirm the impairing effects of central CRF-R activation on maternal behavior and postpartum anxiety.

We further focused on the BNST due to its importance in mediating maternal care (Numan and Insel, 2003), maternal aggression (Bosch et al., 2010; Bosch, 2011; Caughey et al., 2011), and anxiety (Sahuque et al., 2006; Walker et al., 2009). Importantly, the BNST contains most members of the CRF family, including CRF (Potter et al., 1994), Ucn 2 (Reyes et al., 2001), and Ucn 3 (Lewis et al., 2001), as well as CRF-R1 and CRF-R2 (Potter et al., 1994; Chalmers et al., 1995). We found no differences in either CRF-R1 or CRF-R2 mRNA within the mBNST or the pBNST between virgin and lactating rats (Fig. 2). However, CRF-R2 mRNA expression was higher in the pBNST compared with the mBNST. Therefore, we hypothesize that CRF-R2 might play a special role in the pBNST, but that CRF-R1 could contribute equally to possible behavioral changes.

Intra-mpBNST application of either the CRF-R1 or CRF-R2 antagonist had no effect on nursing behavior under nonstress conditions. This indicates a minimal activation of the CRF-R under basal conditions during lactation and thus strengthens the hypothesis that downregulation of the CRF system in the maternal brain is vital. However, infusion of either agonist reduced nursing behavior in a time-dependent manner: the effects of the CRF-R1 agonist were rapid, whereas those of the CRF-R2 agonist were delayed. At the same time, the dams displayed more off-nest behaviors; CRF-R1-agonist-treated dams showed more locomotion and self-grooming, whereas CRF-R2-agonist-treated dams showed more sleeping/resting (Table 3). The time-delayed effect 
of the CRF-R2 agonist might be due to a longer latency until the agonist exerts its actions under basal conditions (Pelleymounter et al., 2004; D'Anna et al., 2005; D'Anna and Gammie, 2009). Therefore, the relative quiescence of both receptor subtypes in the mpBNST is necessary for the expression of appropriate maternal care under basal conditions. Because CRF-R mRNA expression was not different (Fig. 2) and CRF mRNA levels are elevated in the pBNST compared with virgin females (Walker et al., 2001), the proposed quiescence could result from either reduced CRF-R protein expression or reduced $\mathrm{CRF} / \mathrm{Ucn}$ release. This might result from reduced noradrenergic input to the BNST (Forray and Gysling, 2004) or reduced noradrenergic activity within the BNST (Smith et al., 2012) postpartum. In addition, increased oxytocin receptor binding within the BNST postpartum (Bosch et al., 2010) might attenuate the activity of CRF neurons, as has been shown for the paraventricular nucleus (Windle et al., 2004) and, moreover, has been proposed recently for the BNST (Dabrowska et al., 2013). Furthermore, CRF neurons projecting to the BNST from the central amygdala express reduced levels of CRF mRNA during lactation (Walker et al., 2001), thus supporting reduced CRF-R activation also within the mpBNST.

However, after stressor exposure, distinct roles for CRF-R1 and CRF-R2 emerged during subsequent maternal care observation. ABN reflecting the quality of maternal care returned rapidly to prestress levels only in the CRF-R2-antagonist-treated group. The occurrence of nursing reflecting the quantity of maternal care was affected by both receptor antagonists, because a small but significant decrease in nursing after the maternal defense test was prevented by intra-mpBNST administration of both the CRF-R1 and CRF-R2 antagonist.

In contrast to maternal care, we did not find any changes in maternal motivation after subtype-specific CRF-R manipulations within the mpBNST. This seems to be contrary to our own results, because we showed a trend for reduced maternal motivation in the CRF-R1/2-agonist-treated rats (Experiment 1). However, one has to distinguish between central-and thus very broad-receptor manipulation versus local agonism/antagonism of CRF-R within the mpBNST (Bosch, 2011). Because the BNST has not been reported to mediate maternal motivation, the lack of an effect after intra-mpBNST manipulation was anticipated.

With respect to maternal aggression, activation and blockade of CRF-R2 (but not CRF-R1) abolished and increased maternal aggression, respectively (Fig. 5). Interestingly, the CRF-R2 agonist elicited an immediate behavioral effect in a stressful situation, in contrast to basal conditions. These findings support our hypothesis that CRF-R activation in the mpBNST needs to be low during lactation for appropriate maternal behavior to occur. In addition, this further highlights the importance of the CRF-R2 subtype in the regulation of maternal behavior. Consistent with this, CRF-R2, but not CRF-R1, within the lateral septum mediate maternal aggression in lactating mice (Gammie et al., 2005; D'Anna and Gammie, 2009). Therefore, signal transmission via
CRF-R2 modulates maternal aggressive behavior, at least within the mpBNST and the lateral septum.

In addition to maternal behavior, manipulation of CRF-R activity within the mpBNST also affected anxiety-related behavior (Fig. 6). Activation of CRF-R1 was anxiogenic, whereas blockade of CRF-R1 or CRF-R2 was anxiolytic in dams. Interestingly, CRF-R1 activation in lactating rats was anxiogenic at a dose that was not effective in male rats. However, a 2.5-fold higher dose elicits an anxiogenic effect in males (S.M.K. and O.J.B., unpublished data), thereby confirming a previous study showing a similar dose-dependent effect on anxiety (Sahuque et al., 2006). This suggests a higher activation threshold in males. Furthermore, the CRF-R1 or CRF-R2 antagonists reduced anxiety-related behavior in the lactating females, but not in males, which indicates that these antagonists have anxiolytic actions only in combination with previous activation of the receptor in males (Sahuque et al., 2006). Interestingly, the anxiolytic effects of both antagonists were also found in virgin rats, suggesting a higher basal activity of intra-mpBNST CRF-R in females. Therefore, the higher basal activity and the lower activation threshold in females renders the system more sensitive and potentially vulnerable, as shown for the locus ceruleus (Valentino et al., 2013). Interestingly, a recent study demonstrated that CRF infusions into the dorsal raphe nucleus of female mice had no effect, whereas the same treatment affected anxiety in males (Howerton et al., 2014). However, our study is the first to provide evidence that the regulation of emotionality within the BNST by the CRF system is sexually dimorphic and independent of reproductive status.

Regarding the lack of effect on anxiety-related behavior after CRF-R2 activation with stresscopin in lactating rats, it is possible that the dose used was subthreshold or that the agonist requires more time to elicit an anxiogenic-like response. Indeed, the CRF-R2 ligand Ucn 2, which shares high homology with stress- 
copin and binds with similar high affinity to CRF-R2 (Reyes et al., 2001), exerts its anxiogenic effect only $4 \mathrm{~h}$ after central infusion in male rats (Pelleymounter et al., 2002; Valdez et al., 2002; Pelleymounter et al., 2004). The role of CRF-R2 in anxiety-related behavior appears to be complex, especially with respect to CRFR2-knock-out mice (Reul and Holsboer, 2002). The region- and neuron-specific location of receptors, and thus the differential modulation of neurotransmitter systems, is likely responsible for an anxiogenic or anxiolytic behavioral outcome after CRF-R2 activation.

In conclusion, low CRF-R activation within the mpBNST postpartum is an indispensable prerequisite for the adequate rearing and defense of the offspring. Because dysregulation of the mother's CRF system is evident in postpartum mood disorders, our findings serve to better understand the fine-tuned regulation of the maternal brain, especially under stressful conditions.

\section{References}

Bosch OJ (2011) Maternal nurturing is dependent on her innate anxiety: the behavioral roles of brain oxytocin and vasopressin. Horm Behav 59:202212. CrossRef Medline

Bosch OJ (2013) Maternal aggression in rodents: Brain oxytocin and vasopressin mediate pup defence. Philos Trans R Soc Lond B Biol Sci 368: 20130085. CrossRef Medline

Bosch OJ, Neumann ID (2008) Brain vasopressin is an important regulator of maternal behavior independent of dams' trait anxiety. Proc Natl Acad Sci U S A 105:17139-17144. CrossRef Medline

Bosch OJ, Neumann ID (2012) Both oxytocin and vasopressin are mediators of maternal care and aggression in rodents: from central release to sites of action. Horm Behav 61:293-303. CrossRef Medline

Bosch OJ, Meddle SL, Beiderbeck DI, Douglas AJ, Neumann ID (2005) Brain oxytocin correlates with maternal aggression: link to anxiety. J Neurosci 25:6807-6815. CrossRef Medline

Bosch OJ, Pförtsch J, Beiderbeck DI, Landgraf R, Neumann ID (2010) Maternal behaviour is associated with vasopressin release in the medial preoptic area and bed nucleus of the stria terminalis in the rat. J Neuroendocrinol 22:420-429. CrossRef Medline

Bruchas MR, Land BB, Lemos JC, Chavkin C (2009) CRF1-R activation of the dynorphin/kappa opioid system in the mouse basolateral amygdala mediates anxiety-like behavior. PLoS One 4:e8528. CrossRef Medline

Brummelte S, Galea LA (2010) Depression during pregnancy and postpartum: contribution of stress and ovarian hormones. Prog Neuropsychopharmacol Biol Psychiatry 34:766-776. CrossRef Medline

Brunton PJ, McKay AJ, Ochedalski T, Piastowska A, Rebas E, Lachowicz A, Russell JA (2009) Central opioid inhibition of neuroendocrine stress responses in pregnancy in the rat is induced by the neurosteroid allopregnanolone. J Neurosci 29:6449-6460. CrossRef Medline

Brunton PJ, Donadio MV, Russell JA (2011) Sex differences in prenatally programmed anxiety behaviour in rats: differential corticotropinreleasing hormone receptor mRNA expression in the amygdaloid complex. Stress 14:634-643. CrossRef Medline

Caughey SD, Klampfl SM, Bishop VR, Pfoertsch J, Neumann ID, Bosch OJ, Meddle SL (2011) Changes in the intensity of maternal aggression and central oxytocin and vasopressin Vla receptors across the peripartum period in the rat. J Neuroendocrinol 23:1113-1124. CrossRef Medline

Chalmers DT, Lovenberg TW, De Souza EB (1995) Localization of novel corticotropin-releasing factor receptor (CRF2) mRNA expression to specific subcortical nuclei in rat brain: comparison with CRF1 receptor mRNA expression. J Neurosci 15:6340-6350. Medline

Dabrowska J, Hazra R, Guo JD, Dewitt S, Rainnie DG (2013) Central CRF neurons are not created equal: phenotypic differences in CRF-containing neurons of the rat paraventricular hypothalamus and the bed nucleus of the stria terminalis. Front Neurosci 7:156. CrossRef Medline

da Costa AP, Ma X, Ingram CD, Lightman SL, Aguilera G (2001) Hypothalamic and amygdaloid corticotropin-releasing hormone (CRH) and CRH receptor-1 mRNA expression in the stress-hyporesponsive late pregnant and early lactating rat. Brain Res Mol Brain Res 91:119-130. CrossRef Medline

D’Anna KL, Gammie SC (2009) Activation of corticotropin-releasing factor receptor 2 in lateral septum negatively regulates maternal defense. Behav Neurosci 123:356-368. CrossRef Medline

D’Anna KL, Stevenson SA, Gammie SC (2005) Urocortin 1 and 3 impair maternal defense behavior in mice. Behav Neurosci 119:1061-1071. CrossRef Medline

Deschamps S, Woodside B, Walker CD (2003) Pups presence eliminates the stress hyporesponsiveness of early lactating females to a psychological stress representing a threat to the pups. J Neuroendocrinol 15:486-497. CrossRef Medline

Engelmann M, Ebner K, Landgraf R, Holsboer F, Wotjakl CT (1999) Emotional stress triggers intrahypothalamic but not peripheral release of oxytocin in male rats. J Neuroendocrinol 11:867-872. Medline

Forray MI, Gysling K (2004) Role of noradrenergic projections to the bed nucleus of the stria terminalis in the regulation of the hypothalamicpituitary-adrenal axis. Brain Res Brain Res Rev 47:145-160. CrossRef Medline

Gammie SC, Negron A, Newman SM, Rhodes JS (2004) Corticotropinreleasing factor inhibits maternal aggression in mice. Behav Neurosci 118:805-814. CrossRef Medline

Gammie SC, Hasen NS, Stevenson SA, Bale TL, D’Anna KL (2005) Elevated stress sensitivity in corticotropin-releasing factor receptor 2 deficient mice decreases maternal, but not intermale aggression. Behav Brain Res 160:169-177. CrossRef Medline

Hauger RL, Grigoriadis DE, Dallman MF, Plotsky PM, Vale WW, Dautzenberg FM (2003) International Union of Pharmacology. XXXVI. Current status of the nomenclature for receptors for corticotropin-releasing factor and their ligands. Pharmacol Rev 55:21-26. CrossRef Medline

Hauger RL, Risbrough V, Oakley RH, Olivares-Reyes JA, Dautzenberg FM (2009) Role of CRF receptor signaling in stress vulnerability, anxiety, and depression. Ann N Y Acad Sci 1179:120-143. CrossRef Medline

Heinrichs SC (2003) Modulation of social learning in rats by brain corticotropin-releasing factor. Brain Res 994:107-114. CrossRef Medline

Howerton AR, Roland AV, Fluharty JM, Marshall A, Chen A, Daniels D, Beck SG, Bale TL (2014) Sex differences in corticotropin-releasing factor receptor-1 action within the dorsal raphe nucleus in stress responsivity. Biol Psychiatry 75:873-883. CrossRef Medline

Hsu SY, Hsueh AJ (2001) Human stresscopin and stresscopin-related peptide are selective ligands for the type 2 corticotropin-releasing hormone receptor. Nat Med 7:605-611. CrossRef Medline

Jones DN, Kortekaas R, Slade PD, Middlemiss DN, Hagan JJ (1998) The behavioural effects of corticotropin-releasing factor-related peptides in rats. Psychopharmacology (Berl) 138:124-132. CrossRef Medline

Klampfl SM, Neumann ID, Bosch OJ (2013) Reduced brain corticotropinreleasing factor receptor activation is required for adequate maternal care and maternal aggression in lactating rats. Eur J Neurosci 38:2742-2750. CrossRef Medline

Koob GF, Thatcher-Britton K (1985) Stimulant and anxiogenic effects of corticotropin releasing factor. Prog Clin Biol Res 192:499-506. Medline

Lee Y, Davis M (1997) Role of the hippocampus, the bed nucleus of the stria terminalis, and the amygdala in the excitatory effect of corticotropinreleasing hormone on the acoustic startle reflex. J Neurosci 17:64346446. Medline

Lewis K, Li C, Perrin MH, Blount A, Kunitake K, Donaldson C, Vaughan J, Reyes TM, Gulyas J, Fischer W, Bilezikjian L, Rivier J, Sawchenko PE, Vale WW (2001) Identification of urocortin III, an additional member of the corticotropin-releasing factor (CRF) family with high affinity for the CRF2 receptor. Proc Natl Acad Sci U S A 98:7570-7575. CrossRef Medline

Li C, Vaughan J, Sawchenko PE, Vale WW (2002) Urocortin IIIimmunoreactive projections in rat brain: partial overlap with sites of type 2 corticotrophin-releasing factor receptor expression. J Neurosci 22:9911001. Medline

Liang KC, Chen HC, Chen DY (2001) Posttraining infusion of norepinephrine and corticotropin releasing factor into the bed nucleus of the stria terminalis enhanced retention in an inhibitory avoidance task. Chin J Physiol 44:33-43. Medline

Lightman SL, Windle RJ, Wood SA, Kershaw YM, Shanks N, Ingram CD (2001) Peripartum plasticity within the hypothalamo-pituitary-adrenal axis. Prog Brain Res 133:111-129. CrossRef Medline

Magalhaes AC, Holmes KD, Dale LB, Comps-Agrar L, Lee D, Yadav PN, Drysdale L, Poulter MO, Roth BL, Pin JP, Anisman H, Ferguson SS 
(2010) CRF receptor 1 regulates anxiety behavior via sensitization of 5-HT2 receptor signaling. Nat Neurosci 13:622-629. CrossRef Medline

Magiakou MA, Mastorakos G, Rabin D, Dubbert B, Gold PW, Chrousos GP (1996) Hypothalamic corticotropin-releasing hormone suppression during the postpartum period: implications for the increase in psychiatric manifestations at this time. J Clin Endocrinol Metab 81:1912-1917. CrossRef Medline

Mele A, Cabib S, Oliverio A, Melchiorri P, Puglisi-Allegra S (1987) Effects of corticotropin releasing factor and sauvagine on social behavior of isolated mice. Peptides 8:935-938. CrossRef Medline

Moreau JL, Kilpatrick G, Jenck F (1997) Urocortin, a novel neuropeptide with anxiogenic-like properties. Neuroreport 8:1697-1701. CrossRef Medline

Neumann ID, Johnstone HA, Hatzinger M, Liebsch G, Shipston M, Russell JA, Landgraf R, Douglas AJ (1998) Attenuated neuroendocrine responses to emotional and physical stressors in pregnant rats involve adenohypophysial changes. J Physiol 508:289-300. Medline

Neumann ID, Torner L, Wigger A (2000) Brain oxytocin: differential inhibition of neuroendocrine stress responses and anxiety-related behaviour in virgin, pregnant and lactating rats. Neuroscience 95:567-575. CrossRef Medline

Neumann ID, Toschi N, Ohl F, Torner L, Krömer SA (2001) Maternal defence as an emotional stressor in female rats: correlation of neuroendocrine and behavioural parameters and involvement of brain oxytocin. Eur J Neurosci 13:1016-1024. CrossRef Medline

Neumann ID, Krömer SA, Bosch OJ (2005) Effects of psycho-social stress during pregnancy on neuroendocrine and behavioural parameters in lactation depend on the genetically determined stress vulnerability. Psychoneuroendocrinology 30:791-806. CrossRef Medline

Numan M, Insel TR (2003) The neurobiology of parental behaviour. In: Hormones, brain, and behavior series (Ball GF, Balthazart J, Nelson RJ, eds), pp 1-343. New York: Springer.

Numan M, Morrell JI, Pfaff DW (1985) Anatomical identification of neurons in selected brain regions associated with maternal behavior deficits induced by knife cuts of the lateral hypothalamus in rats. J Comp Neurol 237:552-564. CrossRef Medline

O’Keane V, Lightman S, Patrick K, Marsh M, Papadopoulos AS, Pawlby S, Seneviratne G, Taylor A, Moore R (2011) Changes in the maternal hypothalamic-pituitary-adrenal axis during the early puerperium may be related to the postpartum 'blues'. J Neuroendocrinol 23:1149-1155. CrossRef Medline

Paxinos G, Watson C (1998) The rat brain in stereotaxic coordinates, Ed 4. Sydney: Academic.

Pedersen CA, Caldwell JD, McGuire M, Evans DL (1991) Corticotropinreleasing hormone inhibits maternal behavior and induces pup-killing. Life Sci 48:1537-1546. CrossRef Medline

Pelleymounter MA, Joppa M, Ling N, Foster AC (2002) Pharmacological evidence supporting a role for central corticotropin-releasing factor(2) receptors in behavioral, but not endocrine, response to environmental stress. J Pharmacol Exp Ther 302:145-152. CrossRef Medline

Pelleymounter MA, Joppa M, Ling N, Foster AC (2004) Behavioral and neuroendocrine effects of the selective CRF2 receptor agonists urocortin II and urocortin III. Peptides 25:659-666. CrossRef Medline

Pellow S, Chopin P, File SE, Briley M (1985) Validation of open:closed arm entries in an elevated plus-maze as a measure of anxiety in the rat. J Neurosci Methods 14:149-167. CrossRef Medline

Potter E, Behan DP, Linton EA, Lowry PJ, Sawchenko PE, Vale WW (1992) The central distribution of a corticotropin-releasing factor (CRF)binding protein predicts multiple sites and modes of interaction with CRF. Proc Natl Acad Sci U S A 89:4192-4196. CrossRef Medline

Potter E, Sutton S, Donaldson C, Chen R, Perrin M, Lewis K, Sawchenko PE, Vale W (1994) Distribution of corticotropin-releasing factor receptor mRNA expression in the rat brain and pituitary. Proc Natl Acad Sci U S A 91:8777-8781. CrossRef Medline

Reul JM, Holsboer F (2002) On the role of corticotropin-releasing hormone receptors in anxiety and depression. Dialogues Clin Neurosci 4:31-46. Medline

Reyes TM, Lewis K, Perrin MH, Kunitake KS, Vaughan J, Arias CA, Hogen- esch JB, Gulyas J, Rivier J, Vale WW, Sawchenko PE (2001) Urocortin II: a member of the corticotropin-releasing factor (CRF) neuropeptide family that is selectively bound by type 2 CRF receptors. Proc Natl Acad Sci U S A 98:2843-2848. CrossRef Medline

Sahuque LL, Kullberg EF, McGeehan AJ, Kinder JR, Hicks MP, Blanton MG, Janak PH, Olive MF (2006) Anxiogenic and aversive effects of corticotropin-releasing factor (CRF) in the bed nucleus of the stria terminalis in the rat: role of CRF receptor subtypes. Psychopharmacology (Berl) 186:122-132. CrossRef Medline

Saltzman W, Boettcher CA, Post JL, Abbott DH (2011) Inhibition of maternal behaviour by central infusion of corticotrophin-releasing hormone in marmoset monkeys. J Neuroendocrinol 23:1139-1148. CrossRef Medline

Slattery DA, Neumann ID (2010) Chronic icv oxytocin attenuates the pathological high anxiety state of selectively bred Wistar rats. Neuropharmacology 58:56-61. CrossRef Medline

Smith CD, Holschbach MA, Olsewicz J, Lonstein JS (2012) Effects of noradrenergic alpha-2 receptor antagonism or noradrenergic lesions in the ventral bed nucleus of the stria terminalis and medial preoptic area on maternal care in female rats. Psychopharmacology (Berl) 224:263-276. CrossRef Medline

Spiess J, Dautzenberg FM, Sydow S, Hauger RL, Rühmann A, Blank T, Radulovic J (1998) Molecular properties of the CRF receptor. Trends Endocrinol Metab 9:140-145. CrossRef Medline

Spina MG, Merlo-Pich E, Akwa Y, Balducci C, Basso AM, Zorrilla EP, Britton KT, Rivier J, Vale WW, Koob GF (2002) Time-dependent induction of anxiogenic-like effects after central infusion of urocortin or corticotropinreleasing factor in the rat. Psychopharmacology (Berl) 160:113-121. CrossRef Medline

Stern JM, Johnson SK (1990) Ventral somatosensory determinants of nursing behavior in Norway rats. I. Effects of variations in the quality and quantity of pup stimuli. Physiol Behav 47:993-1011. CrossRef Medline

Tazi A, Dantzer R, Le Moal M, Rivier J, Vale W, Koob GF (1987) Corticotropin-releasing factor antagonist blocks stress-induced fighting in rats. Regul Pept 18:37-42. CrossRef Medline

Terkel J, Bridges RS, Sawyer CH (1979) Effects of transecting lateral neural connections of the medial preoptic area on maternal behavior in the rat: nest building, pup retrieval and prolactin secretion. Brain Res 169:369380. CrossRef Medline

Valdez GR, Inoue K, Koob GF, Rivier J, Vale W, Zorrilla EP (2002) Human urocortin II: mild locomotor suppressive and delayed anxiolytic-like effects of a novel corticotropin-releasing factor related peptide. Brain Res 943:142-150. CrossRef Medline

Vale W, Spiess J, Rivier C, Rivier J (1981) Characterization of a 41-residue ovine hypothalamic peptide that stimulates secretion of corticotropin and beta-endorphin. Science 213:1394-1397. CrossRef Medline

Valentino RJ, Bangasser D, Van Bockstaele EJ (2013) Sex-biased stress signaling: the corticotropin-releasing factor receptor as a model. Mol Pharmacol 83:737-745. CrossRef Medline

van Leengoed E, Kerker E, Swanson HH (1987) Inhibition of post-partum maternal behaviour in the rat by injecting an oxytocin antagonist into the cerebral ventricles. J Endocrinol 112:275-282. CrossRef Medline

Waldherr M, Neumann ID (2007) Centrally released oxytocin mediates mating-induced anxiolysis in male rats. Proc Natl Acad Sci U S A 104: 16681-16684. CrossRef Medline

Walker CD, Toufexis DJ, Burlet A (2001) Hypothalamic and limbic expression of CRF and vasopressin during lactation: implications for the control of ACTH secretion and stress hyporesponsiveness. Prog Brain Res 133: 99-110. CrossRef Medline

Walker DL, Miles LA, Davis M (2009) Selective participation of the bed nucleus of the stria terminalis and CRF in sustained anxiety-like versus phasic fear-like responses. Prog Neuropsychopharmacol Biol Psychiatry 33:1291-1308. CrossRef Medline

Windle RJ, Kershaw YM, Shanks N, Wood SA, Lightman SL, Ingram CD (2004) Oxytocin attenuates stress-induced c-fos mRNA expression in specific forebrain regions associated with modulation of hypothalamopituitary-adrenal activity. J Neurosci 24:2974-2982. CrossRef Medline 